\title{
Oligonucleotide-based theranostic nanoparticles in cancer therapy
}

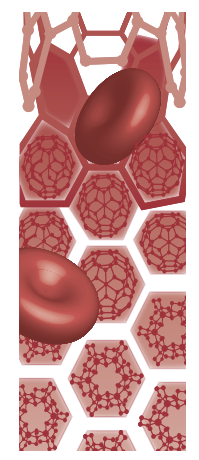

Theranostic approaches, combining the functionality of both therapy and imaging, have shown potential in cancer nanomedicine. Oligonucleotides such as small interfering RNA and microRNA, which are powerful therapeutic agents, have been effectively employed in theranostic systems against various cancers. Nanoparticles are used to deliver oligonucleotides into tumors by passive or active targeting while protecting the oligonucleotides from nucleases in the extracellular environment. The use of quantum dots, iron oxide nanoparticles and gold nanoparticles and tagging with contrast agents, like fluorescent dyes, optical or magnetic agents and various radioisotopes, has facilitated early detection of tumors and evaluation of therapeutic efficacy. In this article, we review the advantages of theranostic applications in cancer therapy and imaging, with special attention to oligonucleotide-based therapeutics.

First draft submitted: 30 January 2016; Accepted for publication: 15 March 2016; Published online: 22 April 2016

Keywords: cancer imaging $\bullet$ cancer therapy $\bullet$ nanoparticle $\bullet$ oligonucleotide $\bullet$ theranostics

Since the first use of nanoparticles in medicine in the late 1960 s by P Speiser, nanoparticle research and applications have advanced significantly [1-3]. In that time nanoparticles have been widely used for drug delivery, especially as vaccine carriers for slow and controlled release. In the last decade, however, nanoparticles have been increasingly used for imaging purposes associated with fluorescence labeling for biological studies [4-6], diagnostic identification of pathogens [7,8], gene delivery [9-11], detection of proteins [12,13], probing of DNA structure [14,15], tissue engineering [16,17], tumor destruction via hyperthermia [18,19], separation and purification of biological molecules and cells $[20,21]$ and contrast enhancement in MRI [22,23].

In recent years, implementation of nanoparticles in theranostic approaches has gained much attention. Theranostics (the term was coined by J Funkhouser in 1998) is based on combining therapy and diagnosis, which is one of the most important goals in cancer research [24-26]. By integrating diagnosis and therapy, theranostics can reduce delays in treatment and improve patient care and it has become an essential component of personalized cancer treatment. The reasoning behind theranostics is that if cancer growth is hindered at an early stage, treatment will be easier than at an advanced stage, where most current therapies seem to be ineffective. Theranostic approaches can lead to early detection and definitive treatment of cancer and thereby improve patient survival.

Imaging of tumors is a critical part of diagnostics, staging, radiotherapy planning and evaluation of treatment efficacy. Standard clinical imaging techniques include $\mathrm{x}$-ray computed tomography, MRI and ultrasonography, which are categorized as structural imaging modalities. These in vivo imaging techniques are invaluable for identifying anatomical patterns and getting basic information about tumor location, size and
Reza Shahbazi', Bulent Ozpolat ${ }^{2}$ \& Kezban Ulubayram*,1,3,4

'Department of Nanotechnology \& Nanomedicine, Institute for Graduate Studies in Science \& Engineering, Hacettepe University, Ankara 06532, Turkey

${ }^{2}$ Department of Experimental Therapeutics, The University of Texas MD Anderson Cancer Center, Houston, TX 77030, USA

${ }^{3}$ Department of Basic Pharmaceutical Sciences, Faculty of Pharmacy, Hacettepe University, Ankara 06100, Turkey

${ }^{4}$ Department of Bioengineering, Institute for Graduate Studies in Science \& Engineering, Hacettepe University, Ankara 06532, Turkey *Author for correspondence: Tel.: +903123054018 Fax: +90312311 4777 ukezban@hacettepe.edu.tr 
spread. However, these imaging modalities do not reliably identify tumors that are smaller than $0.5 \mathrm{~cm}$ in diameter or distinguish between benign and cancerous tumors $[27,28]$.

Recently, molecular imaging, which is the integration of molecular biology with in vivo imaging, has enabled investigation of biological processes and diagnosis of diseases based on molecular markers, which usually appear before clinical presentation of disease. Positron emission tomography and single-photon emission computed tomography, the most common molecular imaging modalities, provide only functional information about molecular processes and metabolites, which is indirect and not specific to distinct cells or diseases [2830]. Nanoparticle-based theranostics can facilitate the study of therapeutic response or disease progression by in vivo imaging of biological processes in their physiological environment, in contrast to aggressive in vitro or ex vivo biopsy/cell culture laboratory techniques. Targeted theranostics employing superparamagnetic nanoparticles [31,32], quantum dots (QDs) [33,34] and gold nanoparticles [35,36] have been developed as nanoprobes for optical and magnetic resonance molecular imaging of tumors.

Nanoparticle-based theranostics avoid the disadvantages of conventional contrast agents, which can be associated with adverse effects, toxicity and in some cases cancer recurrence. For instance, the use of high concentrations of iodine-based contrast agents required for computed tomography can be avoided by using gold nanoparticles [28,37]. As a consequence, nanoparticle-based theranostics with maximum imaging capabilities, minimal dose requirements and lowest toxic effects are preferred.

Since the discovery of Ras oncogene [38], the role of genes in cancer has gained increasing appreciation. Around the turn of the 21st century, the Human Genome Project helped scientists identify a wealth of potential molecular targets that are critical drivers of tumor growth and maintenance of invasive and malignant phenotypes. Since then, the roles of many different genes in oncogenesis have been identified, and those genes are now considered molecular targets $[39,40]$. However, development of safe and effective drugs against specific molecular targets requires tremendous effort and time, and as a result, clinical applications can be delayed. Moreover, many potential target genes of interest cannot be targeted by conventional means.

Recent studies have shown that oligonucleotidebased therapeutics can be a potential solution to the challenge of developing highly specific and targeted therapies [40]. However, oligonucleotide-based therapies require safe and effective delivery systems $[41,42]$.
In theranostic applications, oligonucleotides based on DNA or RNA have been successfully integrated with organic, inorganic or polymeric nanoparticles and after successful gene delivery, downregulation or expression of target genes has been observed, as determined by imaging of the cell response.

In this article, we review recent advancements in cancer theranostics with a special focus on nanoparticle-oligonucleotide systems (oligonanotherapeutics). We discuss highly specific potential molecular targets and nanoparticles used for either targeted delivery or gene therapy. We pay particular attention to conjugation of oligonucleotides or imaging moieties to nanoparticles. We also discuss theranostic applications of oligonanotherapeutics for different cancers.

\section{Importance of oligonucleotide-based theranostics in cancer therapy}

Cancer is the most common cause of the death after heart disease, causing approximately one in five deaths. Cancer is caused by complex processes directly related to cell division and may be induced by exogenous agents. The hallmark of cancer is uncontrolled cell growth leading to tumor formation. The US FDA has approved many anticancer drugs, such as docetaxel, paclitaxel, doxorubicin, vincristine, 5-fluorouracil, daunorubicin, methotrexate and gemcitabine. However, multidrug resistance, narrow therapeutic indices, toxic effects, bone marrow depression and gastrointestinal disorders limit the use of these agents considerably and point to the need for more effective therapeutic agents [43].

In 2004, the FDA recommended that efforts be focused on the search for innovative personalized cancer treatments that would have high efficacy and low side effects. In such personalized approaches, pretreatment diagnostic testing is performed in order to select the optimal therapy based on the patient's genetic profile and/or other molecular or cellular characteristics. Theranostics, therefore, can play an integral role in personalized cancer treatment.

Nanosystems for diagnosis, drug delivery and monitoring of therapeutic response are being extensively researched by investigators in the field of drug or gene delivery and are anticipated to play a critical role in personalized medicine (Figure 1). Studies have shown that in addition to increasing the efficacy of therapeutic agents, nanoparticle-based theranostics can be used for pre- and post-treatment assessment of tumors by imaging tools such as computed tomography, MRI, fluorescence, ultrasonography and positron emission tomography $[43,44]$. Most types of nanoparticles used in theranostics, such as QDs, gold nanoparticles, iron oxide nanoparticles (IONPs) and silica nanoparticles, are already being used 
as imaging agents and have been the subject of extensive research for cancer imaging. These types of nanoparticles are currently the best choice for developing nanoparticlebased theranostics. In cancer therapy, these nanoparticles ameliorate the pharmacokinetics of therapeutic agents, and by exploiting the enhanced permeability and retention effect in tumors, they reduce the adverse side effects associated with systematic administration of therapeutics to the target site [44,45].

In addition to the above characteristics, nanoparticles in theranostic applications can be used to deliver RNA-based therapeutics using small interfering RNA (siRNA), microRNA (miRNA) or small hairpin RNA (shRNA). These novel therapeutics are negatively charged, hydrophilic molecules that must penetrate the hydrophobic plasma membrane to initiate their therapeutic effect $[46,47]$. Encapsulating these oligonucleotides inside nanoparticles or attaching them to the nanoparticle surface can protect them from nucleaseinduced degradation and promote safety, stability and effective delivery.

Different types of nanoparticles can be used for different imaging techniques: for example, superparamagnetic iron oxide (SPIO) nanoparticles for MRI [48], gold nanoparticles for computed tomography [49], QDs for near-infrared (NIR) fluorescence imaging [50] and radiolabeled nanoparticles for positron emission tomography [51]. However, important parameters like nanoparticle size and surface properties need to be optimized in accordance with the planned treatment. For example, nanoparticles smaller than $10 \mathrm{~nm}$ in diameter are quickly excreted by the renal system, and nanoparticles larger than $200 \mathrm{~nm}$ are mostly retained in the spleen [52]. In some applications that focus on siRNA delivery to the liver or tumor, nanoparticle sizes between 10 and $200 \mathrm{~nm}$ are often considered ideal, as such nanoparticles can readily cross the large fenestrae in the liver or the leaky vasculature in tumors to deliver the therapeutic payload to the cells. In recent studies, advanced theranostic approaches have been developed to increase treatment specificity. Most such approaches use a 'smart' delivery system in which a targeting ligand specifically interacts with diseased tissues and the therapeutic agent selectively penetrates tumor cells [52,53].

To summarize, theranostics using highly specific oligonucleotide-based therapeutics can facilitate early detection of tumorigenesis via precise imaging nanoplatforms, allowing timely administration of treatment.

\section{Oligonucleotide-based cancer therapeutics}

Therapeutics based on oligonucleotides may have the potential to be more specific for cancer treatment compared with other cancer drugs which mostly target both healthy and unhealthy cells. Generally, these kinds of therapeutics act on highly expressed oncogenes or their regulatory pathways, and by downregulating them show their therapeutic efficacy.

\section{Morpholino oligonucleotides}

Morpholino oligonucleotides are nonionic DNA analogs with altered backbone linkages which make them one of the most powerful specific tools for gene/protein inhibition [54-56]. Morpholinos use Watson-Crick base-pairing in order to bind to complementary nucleic acid sequences. They are composed of the four genetic bases (adenine, cytosine, guanine and thymine) interconnected to a morpholine ring, from which the term morpholino oligonucleotide is derived. As this binding is not tighter than binding of analogous DNA and RNA oligomers, so the use of relatively long 25-base morpholinos for antisense gene inhibition is necessary. The backbone structure of morpholinos cause them to be resistant to digestion by nucleases and stabilize in plasma which makes them good candidates for systemic treatment. Also, due to the lack of negative charge in their backbone, morpholinos are less probable to interact nonselectively with cellular proteins $[55,57]$.

\section{siRNAs}

Knockdown or downregulation of genes through RNA interference is one of the enterprising approaches that have been used to regulate gene functions in cancer therapy. siRNAs can be used to downregulate specific pathways in cancer cells while sparing normal tissue. siRNAs are 20- to 25-base-pair noncoding RNAs that can be produced from double-stranded RNA and shRNA by Dicer enzyme cleavage, RNase III nuclease activity or chemical synthesis. Dicer introduces the siRNA to a group of proteins called RNA-inducing silencing complex (RISC), where a single strand with the ability to bind to mRNA is produced by the catalytic component Argonaute [58]. The combination of siRNA-based therapeutics and chemotherapy has shown great potential in eliminating drug resistance and improving therapeutic efficacy $[59,60]$.

siRNAs have been used with breast cancer therapeutics to specifically target C-X-C chemokine receptor 4 [61,62], elongation factor 2 kinase [63], Aurora kinase A [64], beta 3 integrin [65], B-cell chronic lymphocytic leukemia (CLL)/lymphoma 11A gene [66], HER2 [67], tumor p53 gene [68], adenosine triphosphate-binding cassette E1 and eukaryotic release factor 3 [69].

\section{miRNAs}

Another strategy for post-transcriptional silencing of genes is the use of miRNAs against a specific mRNA. miRNAs are 20- to 24-nucleotide double-stranded, endogenous RNA molecules that play a significant 


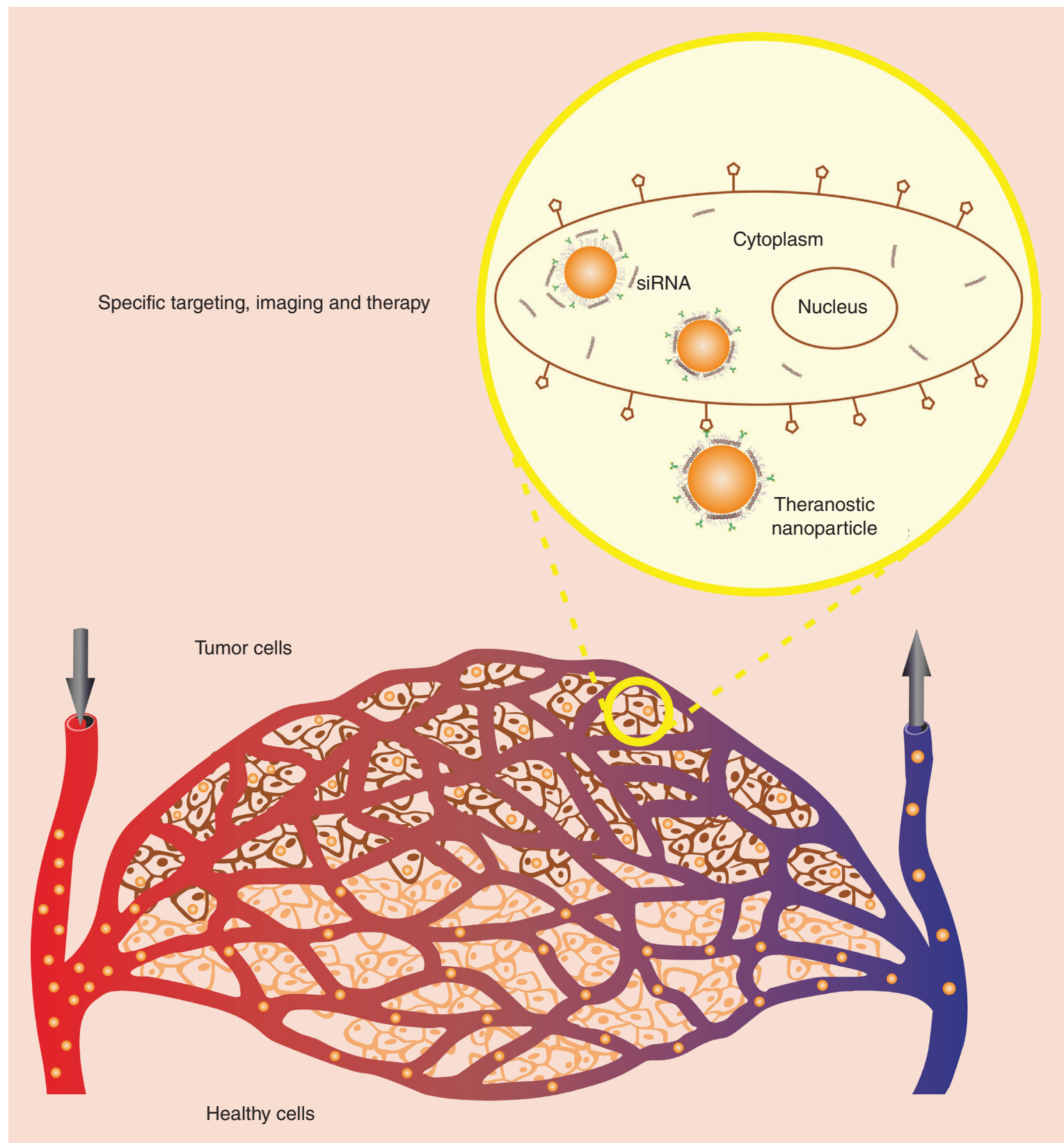

Figure 1. Theranostic approach for cancer imaging and therapy. Oligonucleotide-based theranostic nanoparticles can provide the delivery of therapeutic oligonucleotide sequences along with the specific targeting to the tumor site and imaging the efficiency of therapy.

role in regulating gene expression [70-72]. In contrast to siRNAs, miRNAs can control the expression of more than one mRNA [73]. RNA polymerase II or III starts the transcription of miRNAs, and primary miRNAs produced in the nucleus undergo further processing by a complex composed of the RNase III Drosha and the double-stranded RNA-binding domain protein DiGeorge critical region 8 to yield a long nucleotide. After processing, the miRNA is transported to the cytoplasm and forms an active complex with RISC for the subsequent mRNA degradation.
With their potential to bind to thousands of mRNAs, miRNAs can act as tumor suppressor genes or oncogenes (oncomirs) by downregulating or upregulating specific genes, respectively [72,74]. miRNAs have also been investigated in relation to cancer stem cells and epithelial-mesenchymal transition, which are linked to metastasis and drug resistance [72,75].

\section{shRNAs}

Even though similar functional outcomes can be achieved with shRNA as with siRNA, these mole- 
cules are essentially different, as are their mechanisms of action, RNA interference pathways and off-target effects [76]. In contrast to siRNAs, shRNAs are synthesized in the cell nucleus and are then transported to the cytoplasm, where they express their effects through RISC [77]. shRNAs are transcribed by either RNA polymerase II or III, and the primary transcript has a hairpin-like stem-loop. A pre-shRNA molecule is produced after hairpin measurement and precise processing of the long primary transcripts into individual shRNAs with a 2-nucleotide $3^{\prime}$ overhang by the complex composed of Drosha enzyme and the protein DiGeorge critical region 8 [78,79]. Pre-shRNA is then transported to the cytoplasm by exportin 5, and after it is loaded onto another RNase III complex, composed of Dicer and TAR RNA binding protein/ PKR activating protein, the loop of the hairpin is processed off to form a double-stranded siRNA with 2-nucleotide $3^{\prime}$ overhangs [76,80-84]. As with siRNA, the Dicer-containing complex mediates the loading of shRNA onto the Argonaute 2 protein-containing RISC.

DNA nanocassettes activate transcription of shRNA genes, which are then processed into double-stranded siRNAs for targeted gene silencing [85]. Cassettes that express multiple shRNA sequences allow for a combinatorial RNA interference approach, resulting in greater gene suppression than with single-shRNA cassettes [86-89]. The efficacy of shRNAs can be improved by incorporating mutations and increasing stem length [86,90-92].

\section{Receptor-mediated targeted delivery of theranostics}

An answer to the question of how malignant cells can be targeted without affecting the healthy tissues was first offered by Paul Ehrlich more than 100 years ago [93]. Ehrlich proposed the idea of a magic bullet, whereby a therapeutic agent linked to a molecule with specific affinity for a certain organ would be selectively delivered to the target organ [94]. The discovery of tumor-specific antigens made the idea of a magic bullet real, facilitating delivery of toxic compounds to tumors by specific targeting with antibodies.

Nanoparticle platforms have the potential of being magic bullets for delivery of targeted agents in cancer imaging and therapy. The targeting by nanoparticles can be passive or active. Localization of nanoparticles within the tumor microenvironment is achieved by passive targeting. Active targeting enables more efficient and specific uptake of nanoparticles by tumor cells themselves [95]. Thus, safe systemic therapy, with selective delivery of toxic agents to the tumor, leaving normal tissues unharmed, can be achieved by active targeting with nanoparticle-based therapeutics and targeted delivery can be confirmed by imaging [85].

\section{Ligands}

Targeting moieties such as transferrin and folic acid have been used to functionalize the surface of nanoparticles. The very high selectivity and avidity of these targeting moieties have made them attractive tools for targeting cancer cells. Transferrin, a glycoprotein that transports iron into cells by binding to transferrin receptors on the surface of the cells [96], is up-regulated on metastatic and drug-resistant malignant cells to levels that can be up to 100 times higher than in healthy cells [97-99]. Folic acid is a vitamin that is required for biosynthesis of purines and pyrimidines [100]. The lowaffinity reduced-folate carrier present in almost all cells and the high-affinity glycosylphosphatidylinositollinked folate receptor, which has a very limited distribution, play an important role in cellular uptake of folates [101]. Compared with its levels in normal tissues, the folate receptor is highly upregulated in many human tumors, making it an attractive target for selective delivery of anticancer agents [97,99,102].

\section{Antibodies}

Antibodies were among the first agents used for targeting nanoparticles to specific cell types based on the cells' surface antigens [103]. These targeting agents have remarkably high binding affinity and selectivity due to the presence of two epitope binding sites in a single molecule [104]. Monoclonal antibodies have been used with nanoparticles to target human epidermal growth factor receptor 2 (HER2) [103,105,106], epidermal growth factor receptor [107,108], transferrin receptor [109,110], B-lymphocyte antigen CD20 [111] and prostate-specific membrane antigen (PSMA) [85,112,113].

\section{Antibody fragments}

Antibody fragments have also been used for targeted delivery of nanoparticles, with antigen-binding fragments [114,115] and single-chain variable fragments [116,117] being the most commonly investigated [97,99,102]. Antigen-binding fragments contain one constant and one variable domain for the heavy chain and one constant and one variable domain for the light chain, whereas single-chain variable fragments are combinations of the variable regions of the heavy and light chains $[99,118]$.

\section{Aptamers}

Recently, aptamers have been widely used for targeted delivery of nanoparticles. Aptamers are chemically synthesized single-stranded DNA or RNA oligonucleotides with folded secondary or tertiary 3D structures. 
They can bind to specific biological targets, like proteins. Their high targeting sensitivity and specificity are comparable to those of antibodies [119]. Aptamers are synthesized for a certain target by a repetitive in vitro selective process called 'systemic evolution of ligands by exponential enrichment' [120] .

Aptamers have some advantages over agents such as antibodies, including easier production, the potential for scaling up at a low cost, low batch-to-batch variability [121], selectivity for a wide range of targets [122], much greater stability (with respect to biological degradation, heat, $\mathrm{pH}$ and organic solvents) [122], transport at ambient temperatures and long-term storage [100], slow degradation kinetics, multiple denaturation and renaturation times without significant loss of activity [123], easy chemical modification with functional groups [121], lack of immunogenicity [121], smaller size $(\sim 1-2 \mathrm{~nm}$ diameter, $<10 \mathrm{kDa})$ and better tissue penetration in solid tumors [99,122].

Aptamers that have been used for targeted delivery of nanoparticles include A10 RNA, for PSMA [124,125]; AS1411, for nucleolin cell membrane protein [126]; anti-MUC1, for MUC1-positive cancer cells [127]; RNA-based anti-CD30, for anaplastic large cell lymphoma cells [128] and $\mathrm{sgc} 8 \mathrm{c}$, for protein tyrosine kinase 7 transmembrane protein [129].

\section{Designing theranostic nanoparticles}

Before proposing a theranostic approach for cancer treatment, apart from choosing the right therapeutic oligonucleotide, some important factors should be considered (Figure 2).

\section{Type of the nanoparticle}

Along with the two indispensable aspects, safety and efficacy of nanoparticles for oligonucleotide delivery, some other factors also need to be carefully regarded. It is very important to decide whether the therapeutic payload is going to be encapsulated inside the nanoparticle or conjugated to the surface. If it is going to be encapsulated, nanoparticles such as liposomes, polymeric nanoparticles, hollow or porous silica nanoparticles, hollow gold nanoparticles or hollow IONPs, can be used. With inorganic nanoparticles conjugation of the oligonucleotides to the surface of the nanoparticle is the most common approach.

Two types of binding methods are used for the conjugation of oligonucleotides to nanoparticles.

\section{Electrostatic interactions between the positively} charged nanoparticles \& oligonucleotides

Electrostatic interactions of oligonucleotides with nanoparticles can be achieved by using polymers such as poly(ethyleneimine) (PEI), poly-L-lysine, chitosan, poly(amidoamine), poly(propyleneimide) or newly synthesized cationic polymers [130]. PEI (molecular weight: $25 \mathrm{kDa}$ ) is the gold standard in gene delivery applications [131,132]. By coating gold nanoparticles with the charge-reversal polymer poly(allylamine)citraconic anhydride and PEI using the layer-by-layer technique, Guo et al. were able to induce charge reversal and release of siRNA in the acidic environment of the HeLa cells [132]. The researchers concluded that this approach promotes the escape of gold nanoparticle/nucleic acid complexes from the endosome/lysosome and release of oligonucleotides into the cytoplasm. Combinatorial synthesis and parallel screening approaches can help identify candidate polymers that have high gene delivery and gene silencing efficacies [86,133].

\section{Covalent binding of the oligonucleotides to nanoparticles}

Oligonucleotides can be bound to nanoparticles either through functional groups on nanoparticles or using intermediary linkers. Giljohann et al. created densely siRNA-functionalized polyvalent gold nanoparticles by inducing covalent interaction of siRNAs with the nanoparticles through an oligo(ethylene glycol) thiol linker [134]. This functionalization resulted in a conjugate with distinctive properties that made it a potent material in terms of serum stability, cellular uptake and genetic regulation without any chemical modification or the use of auxiliary transfection strategies.

\section{Imaging agent}

With theranostic nanoparticles imaging can be carried out by exploiting the intrinsic characteristic of inorganic materials such as gold, magnetite, cadmium selenide, etc. when they are precisely synthesized in nanometer size range. In this regard, the delivery vehicle can leverage the imaging by its intrinsic characteristic. Nevertheless, there are some pros and cons of using these nanoparticles that are mentioned in this review later on.

Also, other routinely used imaging agents such as organic fluorescent dyes and radioisotopes which are widely used in biological systems can be encapsulated or conjugated to nanoparticles which do not contain any imaging properties. However, low penetration capacity of visible or ultraviolet light, toxic effects and photobleaching have caused that organic dyes mainly be used as imaging cells in vitro. Radioisotopes also have some health issues that need careful attention before use. One of the important advances in imaging is the consideration of fluorescence resonance energy transfer by using metallic nanoparticles and fluorescent dyes like cyanine 5.5 (Cy5.5), fluorescein isothiocya- 


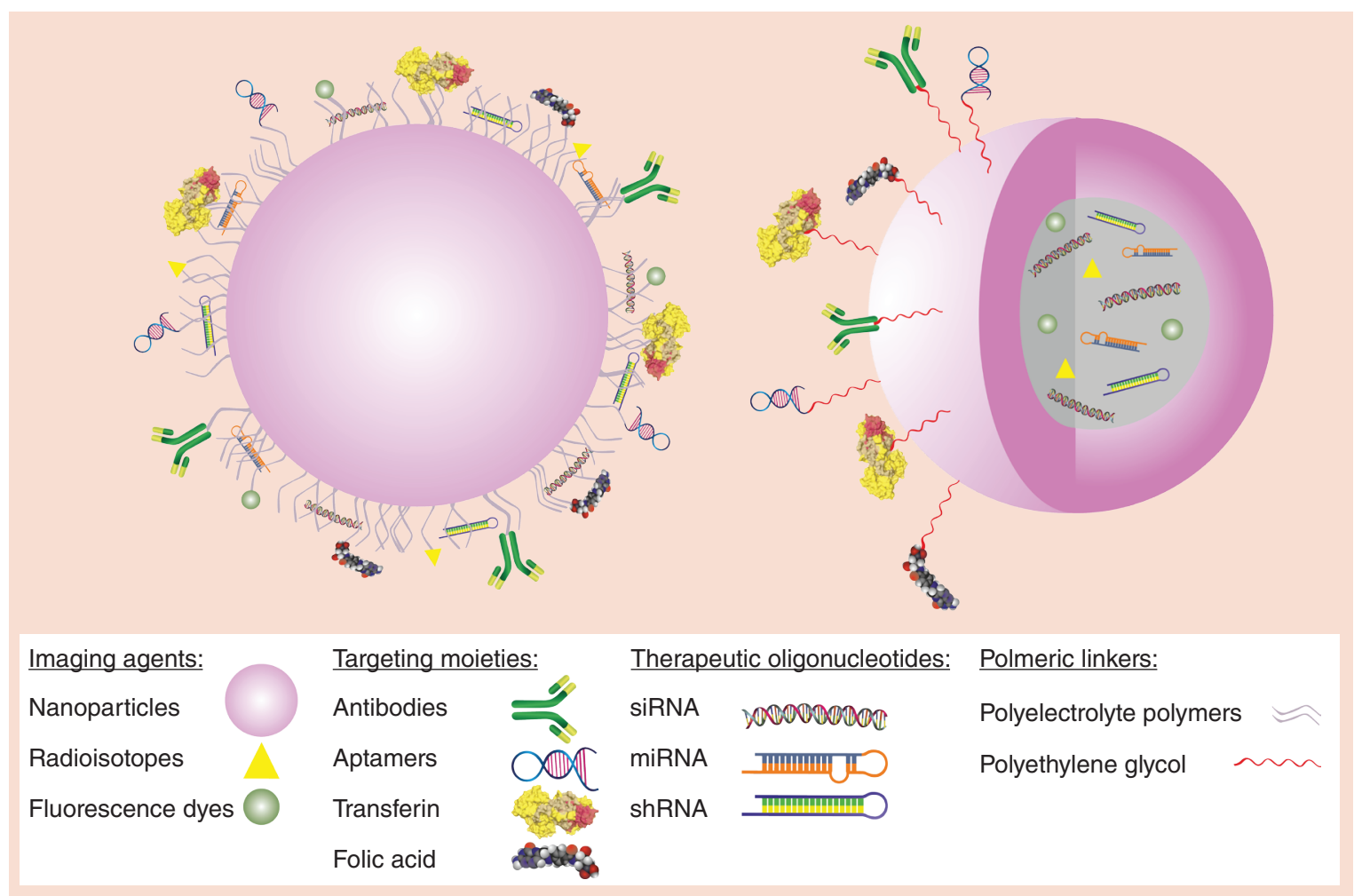

Figure 2. Designing of theranostic nanoparticles.

nate etc. in imaging modalities. It is very important to know that by linking organic dyes via a peptide linker to nanoparticles with fluorescence-quenching characteristics, like gold nanoparticles, photobleaching can be avoided and longer visualization of the cells can be achieved (Figure 2) [26].

\section{Targeting moiety}

As discussed in 'Receptor-Mediated Targeted Delivery of Theranostics' another important moiety that can be included in theranostics is the targeting chain on the nanoparticle surface. For targeted delivery of nanoparticles apart from passive targeting that facilitates the tumor accumulation of nanoparticles, highly specific ligands can be conjugated to the functional groups on the surface of nanoparticles and provide 'magic bullets' capable of targeting the cells of interest. When we are talking about targeting mostly antibodies come to our mind, however, small molecules, which are lowmolecular-weight $(<800 \mathrm{Da})$ organic compounds, can penetrate the cell membrane and interfere with signaling pathways and they are typically used for targets inside the cell. In contrast, most monoclonal antibodies cannot penetrate the plasma membrane and are commonly used for targets outside the cell or on the cell surface [135].

Bahmani et al. investigated the use of NIR fluorescence imaging for detecting HER2 overexpression as a biomarker of ovarian cancer cells and for inducing photothermal destruction of these cells [136]. Indocyanine green was encapsulated within poly(allylamine hydrochloride) chains cross-linked ionically with sodium phosphate, and monoclonal antibodies against HER2 were conjugated to the surface through poly(ethylene glycol) (PEG) chains. The results showed that functionalized nanoconstructs targeted HER2 more effectively than the nonindocyanine green-carrying nonfunctionalized constructs, and greater photothermal destruction of SKOV3 cells was observed with the former.

\section{Oligonucleotide-based theranostic nanoparticles in cancer therapy}

Many different types of nanoparticles such as inorganic, organic and polymeric nanoparticles have been used as theranostics with the purpose of delivering oligonucleotides to cancer cells. Here is the review of the studies that have been performed in recent years (Table 1).

\section{Inorganic nanoparticles}

Due to their unique size and shape-dependent physical and chemical properties, inorganic nanoparticles provide great advantages for imaging and therapy. These nanoparticles offer a unique platform for multifunctionality and multiple ligands such as targeting agents, 
Table 1. Classification of the oligonucleotide-based theranostic nanoparticles used in cancer therapy.

\begin{tabular}{|c|c|c|c|c|}
\hline Type of nanoparticle & $\begin{array}{l}\text { Therapeutic } \\
\text { oligonucleotide }\end{array}$ & Imaging agent & Imaging modality & Ref. \\
\hline Gold nanoparticles & $\begin{array}{l}\text { DNA and siRNA } \\
\text { codelivery for GFP }\end{array}$ & $\begin{array}{l}\text { GFP expression or knock } \\
\text { down }\end{array}$ & Fluorescence microscopy & {$[137]$} \\
\hline SPIO nanoparticles & hTERT siRNA & SPIO nanoparticles & MRI & {$[138]$} \\
\hline Quantum dots (QDs) & $\begin{array}{l}\text { U6-enhanced-GFP (EGFP) } \\
\text { siRNA, survivin siRNA }\end{array}$ & Quantum dots & Fluorescence microscopy & [139] \\
\hline $\begin{array}{l}\text { PEI-modified silica-coated magnetite } \\
\text { nanoparticles }\end{array}$ & VEGF shRNA & Magnetite nanoparticles & MRI & [140] \\
\hline $\begin{array}{l}\text { Manganese-doped magnetism- } \\
\text { engineered iron oxide nanoparticles } \\
\text { coated with bovine serum albumin }\end{array}$ & Anti-GFP siRNA & Iron oxide nanoparticles & MRI & {$[141]$} \\
\hline CdSe/CdS/ZnS QDs & EGFP siRNA & Quantum dots & Fluorescence microscopy & {$[142]$} \\
\hline $\begin{array}{l}\text { 1,4C-1,4Bis-gold nanorod } \\
\text { poly(aminoether) nanoassemblies }\end{array}$ & Luc29 shRNA plasmid & Gold nanorod & $\begin{array}{l}\text { Two-photon induced } \\
\text { luminescence imaging }\end{array}$ & [86] \\
\hline PEGylated liposome & Survivin siRNA & $\begin{array}{l}\text { Gadolinium-containing } \\
\text { lipids, Rhodamine-labeled } \\
\text { cationic liposome, Alexa } \\
\text { Fluor-labeled siRNA }\end{array}$ & $\begin{array}{l}\text { MRI, fluorescence } \\
\text { microscopy }\end{array}$ & [143] \\
\hline $\begin{array}{l}\text { Nanoparticles based on human serum } \\
\text { albumin }\end{array}$ & GL3 siRNA & $\begin{array}{l}\text { macrocyclic gadolinium } \\
\text { complexes }\end{array}$ & MRI & [144] \\
\hline $\begin{array}{l}\text { QD-incorporated solid lipid } \\
\text { nanoparticles }\end{array}$ & $\mathrm{Bcl}-2$ siRNA & Quantum dots & Fluorescence imaging & [145] \\
\hline Liposome-gold nanorod hybrids & PLK-1 siRNA & Gold nanorods & $\begin{array}{l}\text { Multispectral } \\
\text { optoacoustic tomography }\end{array}$ & [146] \\
\hline $\begin{array}{l}\text { Poly(lactic-co-glycolic acid) } \\
\text { nanoparticles }\end{array}$ & Hmgcr siRNA & Polymethine dyes & $\begin{array}{l}\text { Intravital epifluorescence } \\
\text { microscopy }\end{array}$ & {$[147]$} \\
\hline Chitosan-based hybrid nanocomplex & Survivin siRNA & Cy5.5 & NIR fluorescence imaging & [148] \\
\hline $\begin{array}{l}\text { PEI-PEG-cografted polymeric } \\
\text { nanoparticles }\end{array}$ & Choline kinase siRNA & $\begin{array}{l}{\left[{ }^{111} \mid \mathrm{n}\right] 1,4,7,10-} \\
\text { tetraazacyclododecane- } \\
1,4,7,10 \text {-tetraacetic acid }\end{array}$ & $\begin{array}{l}\text { Single-photon emission } \\
\text { computed tomography }\end{array}$ & [85] \\
\hline
\end{tabular}

drugs, oligonucleotides and radioisotopes can be attached onto or encapsulated inside the nanoparticles for the possibility of molecular targeting, therapeutic delivery and multimodal imaging [137].

In a study investigating the use of gold nanoparticles for codelivery of DNA and siRNA, Bishop et al. [138] used the layer-by-layer technique to coat the surface of the gold nanoparticles with different polymers, DNA and siRNA. Since regular citrate-stabilized gold nanoparticles tend to aggregate upon the addition of polyelectrolyte and polymer solutions, 11-mercaptoundecanoic acid was used as the first layer to increase nanoparticle stability for subsequent steps. It is widely known that PEI is an efficient gene transfection agent, but Bishop et al. also tested the poly(amido amine) N,N'-bis(acryloyl) cystamine-3-amino-1-propanol-1-(3-aminopropyl)4-methylpiperazine (BSS-S3-E7, or SS37) and the poly(beta-amino ester) 1-(3-aminopropyl)-4-methyl- piperazine end-terminated poly(1,4-butanediol diacrylate-co-4-amino-1-butanol) (B4-S4-E7, or 447) as layering polymers. The cationic polymer SS37 was used for its ability to promote nucleic acid complexation and for its degradation potential due to its disulfide linkages, which can break apart in a reducing environment like cytosol [139]. 447, a hydrolytically biodegradable polymer with tertiary amines, was used to aid endosomal escape by producing the proton sponge effect [139,140].

PEI was more effective for nucleic acid binding than the degradable and less positively charged polymer 447. However, two layers of PEI coating were less effective and more toxic than the combination of PEI and a degradable polymer. A gene knockdown experiment using nanoparticles $200 \mathrm{~nm}$ in diameter in a green fluorescent protein (GFP)-positive human glioblastoma multiforme cell line (GBM319) showed that the knockdown of GFP achieved by a PEI-DNA-SS37- 
siRNA-447 gold nanoparticle formulation coated with 11-mercaptoundecanoic acid (300 ng DNA and 240 ng of siRNA formulation) was higher than with any other formulation tested, including Lipofectamine 2000. MTS assay for cytotoxicity showed that the relative metabolic activity was about $80 \%$. The 11 -mercaptoundecanoic acid-coated PEI-DNA-447 gold nanoparticle formulation was the most efficacious for GFP expression. These findings indicate that PEI by itself is a very good polymer for nucleic acid binding, but it is not sufficient for efficient transfection, and an outer layer of the biodegradable polymer 447 can enhance the transfection rate. The authors of the study suggested that these layer-by-layer formulations can potentially be used for delivery of imaging and photothermal therapy agents as well as for theranostic purposes. Such formulations can also be used to increase uptake and decrease the concentration of administered siRNA in treatment of many cancers.

Li et al. studied the efficiency of DNA and siRNA transfection by SPIO nanoparticles coated with a disulfide-containing PEI (SSPEI) outer layer [141]. The nanoparticles were approximately $80 \mathrm{~nm}$ in diameter, and after being coated with SSPEI, had a zeta potential of about $+26 \mathrm{mV}$. The researchers hypothesized that these nanoparticles can release DNA or siRNA due to the cleavage of the disulfide bond of SSPEI, thereby inducing high levels of gene expression or downregulation $[142,143]$. For DNA transfection studies the expression level of GFP was evaluated in the MCF-7 breast cancer cell line. SSPEI-SPIO/DNA $(1 \mu \mathrm{g}$ DNA) at a mass ratio of 5:1 produced potent transfection, with an efficiency comparable to that observed with complexes of branched PEI. Although PEI is one of the most effective nonviral gene delivery vectors, it has toxic effects. After comparing the viabilities of cells transfected with branched PEI/DNA and cells transfected with SSPEI-SPIO/DNA ( $\sim 0$ and $\sim 100 \%$, respectively), the researchers concluded that SSPEI-SPIO/DNA was safer and more effective for gene transfection.

$\mathrm{Li}$ et al. also explored the ability of nanoparticles to deliver hTERT siRNA in human liver carcinoma cells (HepG2 cells). Compared with its levels in normal human somatic cells, hTERT mRNA is expressed at extremely high levels in the majority of human cancer cells, making hTERT a specific target for cancer therapy [144-147]. Gene downregulation studies showed efficient SSPEI-SPIO/ hTERT-siRNA (0.5 $\mu \mathrm{g}$ siRNA) uptake and concomitant downregulation of $h T E R T$ mRNA/protein expression and rapid apoptosis in HepG2 cells.

As a theranostic nanoparticle formulation, these nanoparticles provided the imaging ability by MRI. MRI is one of the most widely used imaging techniques in cancer diagnosis. MR images are obtained using longitudinal (T1) and transverse (T2) relaxation. Paramagnetic T1-weighted contrast agents such as gadolinium $\left(\mathrm{Gd}^{3+}\right)$ and manganese $\left(\mathrm{Mn}^{2+}\right)$ chelates are used to increase the $\mathrm{T} 1$ relaxation time, and superparamagnetic $\mathrm{T} 2$-weighted contrast agents such as magnetite $\left(\mathrm{Fe}_{3} \mathrm{O}_{4}\right)$ nanoparticles are used to reduce T2 relaxation times [148]. In vivo $\mathrm{MR}$ images of a nude mouse bearing an HepG2 tumor showed the accumulation of nanoparticles in the tumor at $1-3 \mathrm{~h}$ postintravenous injection of SSPEI-SPIO nanoparticles as the intensity of the signal on a T2-weighted fast spin echo image of the tumor decreased. These findings indicate that SSPEI-SPIO nanoparticles have promise for tumor gene therapy and imaging.

Cho et al. tested magnetic IONPs or QDs conjugated to the amino terminal fragment (ATF) of the urokinase plasminogen activator (uPA) for targeted delivery of siRNA-expressing DNA nanocassettes into tumors [149]. uPA receptor is highly expressed in tumor, angiogenic endothelial and stromal cells in various human cancers [150-153]. Transfection of U6enhanced-GFP (EGFP) siRNA with 56-nm QD/ $\mathrm{uPA} /$ nanocassettes silenced the expression of the transduced EGFP gene in a GFP gene-stable MCF-7 cell line. The researchers suggested that a possible mechanism behind the release of DNA nanocassettes was cleavage of the amide bond between the nanoparticles and DNA nanocassettes. Gene transfection studies showed that U6-Luc siRNA nanocassettes conjugated to QDs with human ATF-targeting ligands (hATFQDs-Luc siRNA) were delivered into MCF-10DCIS human breast cancer cells more efficiently than those conjugated to nontargeted nanoparticles. A noticeable decrease in luciferase activity was observed after uPA receptor-targeted internalization of QD-Luc siRNA. As the number of Luc siRNA nanocassettes on QDs increased from 2 to 10 or 20 , so did the inhibitory effect.

The researchers also investigated the transfection efficiency of hATF-Luc siRNA-IONPs in MIA $\mathrm{PaCa}-2$ pancreatic cancer cells in comparison with that of double-stranded RNA-Luc siRNAs by using the Xenogen IVIS imaging system. A $65 \%$ reduction in luciferase activity was achieved by incubating cells for 48 h with hATF-Luc siRNA-IONPs (20 pmol DNA nanocassettes). The same concentration of Luc siRNAs decreased luciferase activity by 39\% (Figure 3A). In an in vivo experiment, $72 \mathrm{~h}$ after a tail vein injection of hATF-QD-Luc siRNA nanocassettes ( $2 \mathrm{nmol}$ of DNA cassettes), luciferase activity was reduced by $90 \%$ (Figure 3B). Another experiment was aimed at investigating the use of nanoparticles for survivin gene knockdown. Survivin is highly expressed in many human cancers and plays a major role in the blocking of 
apoptosis [154]. Several hATF-QD-conjugated survivin siRNA-expressing DNA nanocassettes produced survivin gene knockdown in MD-MB-231 breast cancer cells along with activation of the apoptotic cell death mediated by high levels of active caspase 3 . Although pancreatic cancer cells are not sensitive to free gemcitabine, the combination of hATF-QD-conjugated survivin siRNA-expressing DNA nanocassettes with $1 \mu \mathrm{M}$ gemcitabine decreased the percentage of viable MIA PaCa-2 cells tremendously, from $94 \%$ in the freedrug-treated cells to $18 \%$. Taken together, the findings indicate that the strategy of using siRNA-expressing DNA nanocassettes with QDs or IONPs can be an effective approach in theranostic applications.

Li et al. designed PEI-modified silica-coated magnetite $\left(\mathrm{Fe}_{3} \mathrm{O}_{4} @ \mathrm{SiO}_{2}\right)$ nanoparticles capable of carrying a high load of VEGF shRNA for VEGF gene silencing and MRI [155]. The $\mathrm{Fe}_{3} \mathrm{O}_{4} @ \mathrm{SiO}_{2} / \mathrm{PEI} / \mathrm{VEGF}$ shRNA nanoparticle formulation silenced VEGF mRNA expression and enhanced gene silencing more efficiently than the control formulation $\left(\mathrm{Fe}_{3} \mathrm{O}_{4} @ \mathrm{SiO}_{2} /\right.$ $\mathrm{PEI} / \mathrm{Sc}$ shRNA). MRI findings showed that these nanoparticles can act as a T2-weighted contrast agent for cancer MRI.

Lee et al. developed all-in-one nanoparticle probes for simultaneous delivery and multimodal imaging [156]. The probes consisted of 15-nm-diameter manganese-doped magnetism-engineered IONPs coated with bovine serum albumin. These nanoparticles can enhance MRI signals because their magnetic moment is higher than that of conventional magnetic IONPs. The nanoparticles were functionalized with an RGD peptide using PEG. RGD peptides have the ability to specifically bind to $\alpha v \beta 3$ integrin, which is expressed abundantly in metastatic tumor cells and tumor endothelial cells and plays a critical role in receptor-mediated endocytosis [157]. Cy5 dyelabeled thiolated siRNAs (HS-siGFP-Cy5) (4 pmol) attached to the surface of nanoparticles through disulfide bonds inhibited the expression of GFP. The cell-targeting ability of the nanoparticles was then examined in breast cancer cells (MDA-MB- 435 cells) expressing $\alpha v \beta 3$ integrin and lung carcinoma cells (A549 cells) deficient in $\alpha v \beta 3$ integrin. In contrast to the images of A549 cells, which showed no change in MR contrast, T2-weighted gradient echo MR images of MDA-MB-435 cells at 3.0 T had strong contrast, which became more intense with increasing amounts of the nanoparticles. Analogous results were obtained in gene silencing experiments. A significant reduction in the intensity of green fluorescence was observed in MDA-MB-435-GFP cells, whereas no notable reduction in fluorescence was observed in A549-GFP cells. These findings demonstrated the effectiveness of
RGD-mediated targeting in both MR imaging and gene silencing.

Jung et al. prepared 7-nm-diameter core-shell $\mathrm{CdSe} / \mathrm{CdS} / \mathrm{ZnS}$ QDs coated with trioctylphosphine oxide or hexadecylamine [158]. Dihydrolipoic acid derivatized with an amine-terminated PEG spacer was added to the formulation to make the QD constructs water-soluble and suitable for conjugation with siRNA $(0.12 \mu \mathrm{M})$. Additionally, two targeting peptides, a thiol-modified RGD peptide and a thiol-modified human immunodeficiency virus Tat-derived peptide, were attached to the siRNA-QDs. Gene silencing efficiency was measured as suppression of EGFP expressed in U87 cells that were genetically modified to express EGFP. Very high levels of siRNA-QDs were observed within U87-EGFP cells due to the synergistic effects of the two transfection peptides, as confirmed by fluorescence microscopy. Toxicity tests showed that prepared nanoparticles in 10-50 nM concentrations were not toxic and cell viability was above $90 \%$.

Ramos and Rege generated 1,4C-1,4Bis-gold nanorod poly(aminoether)-based nanoassemblies using a layer-by-layer deposition approach to investigate the silencing of expressed luciferase protein with shRNA plasmids in 22Rv1-Luc human prostate cancer cells [86]. Up to $55 \%$ silencing of the original luciferase signal was achieved by nanoassemblies delivered by the Luc29 shRNA plasmid. Given that gold nanorods provide highly efficient two-photon induced luminescence both in vitro and in vivo and can absorb excitation wavelengths in the NIR region of the absorption spectrum with minimal tissue scattering and phototoxic effects, two-photon luminescence was successfully used to image these nanoassemblies [159-161]. Gold nanorod-based nanoassemblies are also useful for hyperthermic ablation of cancer cells using NIR lasers $[162,163]$.

\section{Organic nanoparticles}

Kenny et al. designed PEGylated liposome-encapsulated siRNA (LEsiRNA) theranostic nanoparticles with the ability to reduce survivin expression and tumor growth and demonstrated real-time monitoring of delivery by MRI with fluorescence [164]. The average diameter of the LEsiRNA nanoparticles was $88 \pm 1.6$ $\mathrm{nm}$. In vivo MRI showed that $24 \mathrm{~h}$ after tail vein injection of the nanoparticles in mice, signal intensity on the T1-weighted fast spin echo images was increased due to the presence of gadolinium-containing lipids from the nanoparticles. The MR relaxivity of the LEsiRNA nanoparticles was higher than that of clinical MRI contrast agents like gadoterate meglumine. In addition to their effectiveness for imaging, LEsiRNA nanoparticles also caused a significant reduction in 
(A)

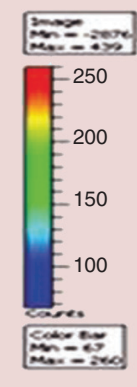

(B)

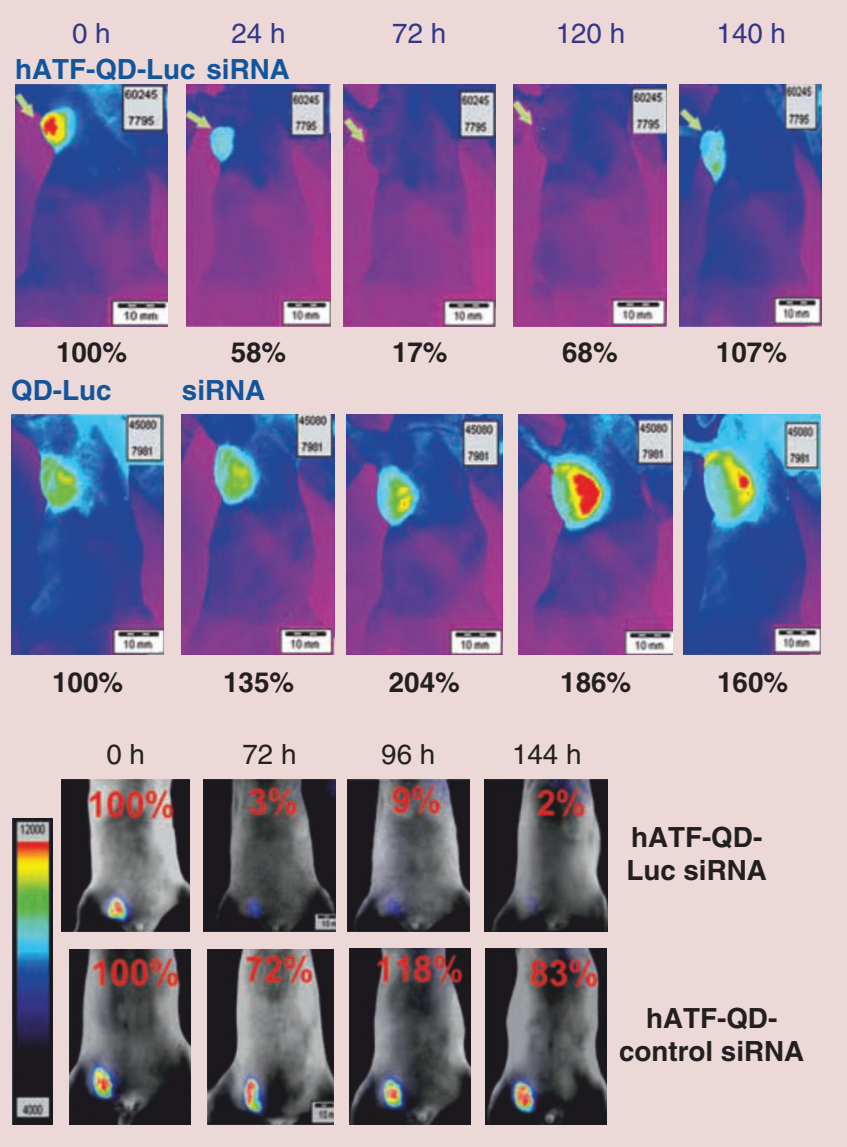

Figure 3. Transfection efficiency of hATF-Luc siRNA-IONPs and hATF-QD-Luc siRNA nanocassettes. (A) Comparison of gene silencing induced by unconjugated RNA-based siRNAs and that induced by targeted nanoparticles carrying siRNA-expressing DNA nanocassettes. (B) Luciferase activity in nude mice bearing MCF-10DCIS human breast tumor xenografts that received hATF-QD-Luc siRNA nanocassettes or nontargeted QD-Luc siRNA nanocassettes (upper panels) and validation of the specific gene silencing effect after systemic delivery of hATF-QD-Luc siRNA or control scrambled-siRNA-carrying nanocassettes (lower panels).

Reprinted with permission from [139] @ 2013 Wiley-VCH.

OVCAR-3 (human ovarian cancer cell line) xenograft tumor growth at 48 and $72 \mathrm{~h}$ postadministration $(2.5$ $\mathrm{mg} / \mathrm{kg}$ of siRNA). Western blot analysis showed that the expression of survivin was reduced after nanoparticle administration. Fluorescence microscopy of tissue slices showed colocalization of the PEGylated bimodal rhodamine-labeled cationic liposome and the Alexa Fluor-labeled siRNA in the tumor. Thus, in addition to the delivery of siRNA, simultaneous monitoring of delivery was also made possible.

Mertz et al. designed theranostic nanoparticles based on human serum albumin for simultaneous gene silencing and MRI applications [165]. The researchers described an effective method based on the use of isobutyramide grafts and their derivatives to assemble different biomacromolecules, composing proteins, at interfaces or in freestanding form $[165,166]$. Nanoparticles were covalently grafted with macro- cyclic gadolinium complexes (1,4,7,10-tetraazacyclododecane-1,4,7,10-tetraacetic acid-Gd) as an MRI contrast agent. The gene silencing efficacy of the nanoparticles was examined in A549luc lung carcinoma cells stably transfected with the pGL3 gene, expressing the firefly luciferase. After 72-h incubation with siRNA/nanoparticles, high levels of inhibition of gene reporter expression were observed in the cells: up to $80 \%$ for non-Gd-grafted nanoparticles and up to $50 \%$ for Gd-grafted nanoparticles. MRI showed that Gd-grafted albumin nanoparticles enhanced MRI contrast over that observed with the control (saline buffer).

Bae et al. developed QD-incorporated solid lipid nanoparticles for anticancer theranostics with the synergistic paclitaxel-siRNA therapeutic combination [167]. Both paclitaxel and Bcl-2 siRNA $(1 \mu \mathrm{g} / \mathrm{ml})$ were delivered successfully into human lung carcinoma 
cells, and the treatment produced synergistic anticancer activities by triggering caspase-mediated apoptosis. Prepared complexe effectively suppressed the Bcl-2 expression down to $52.5 \pm 15.0 \%$. QDs with strong fluorescence intensity within the nanoparticles were visualized in situ, and intracellular translocation of the nanoparticles was observed.

Taruttis et al. prepared liposome-gold nanorod hybrids with optimized-length gold nanorods $(29 \mathrm{~nm}$ AuNR700, $38 \mathrm{~nm}$-AuNR780 and $45 \mathrm{~nm}$-AuNR850) for delivery of PLK-1 siRNA and multispectral optoacoustic tomography [168]. Due to the fact that, higher absorption intensity will lead to the better MSOT resolution the liposomes with $\mathrm{AuNR}_{780}$ were selected for the experiments. Liposomes were labeled with the NIR-797 fluorescent tag to allow validation by fluorescence cryoslicing imaging. In vivo multispectral optoacoustic tomography of liposome vectors using the 4T1 and HT29 tumor cell models showed that the injected dose remained stable at the site of injection after $24 \mathrm{~h}$, protecting the siRNA from being cleared from the tumor and thereby enabling apoptosis (Figure 4).

\section{Polymeric nanoparticles}

Polymeric nanoparticles with their ability to encapsulate therapeutics have shown to be potential nanocarriers for oligonucleotide delivery. These nanoparticles can protect their payload from serum endonucleases and release the entrapped therapeutic timely. Also, oligonucleotides can be introduced during the preparation of nanoparticles and form a nanocomplex capable of gene delivery [169].

Press et al. used poly(lactic-co-glycolic acid) nanoparticles covalently conjugated with fluorescent polymethine dyes for organ-selective imaging and siRNA delivery in mice [170]. Dyes with four sulfonic residues underwent preferential renal elimination, and dyes with only one sulfonic residue underwent hepatobiliary excretion. DY-780 and DY-635 were excreted preferentially via the biliary route. The use of DY-635 facilitated the monitoring of uptake and hepatobiliary clearance by intravital epifluorescence microscopy (Figure 5). Uptake of DY-635 by mouse hepatocytes was rapid, temperature sensitive and sensitive to dosedependent inhibition by cyclosporin A. More than $90 \%$ of DY-635-nanoparticles were cleared by the hepatobiliary system within $1 \mathrm{~h}$. While DY-635 functionalized nanoparticles showed significant uptake by the liver, all the other nanoparticles showed uptake by spleen which indicated the phagocytic clearance.

The researchers theorized that a possible uptake route was immobilization of nanoparticles on the cell surface by the interaction of DY-635 with organic anion-transporting polypeptides and clathrin-mediated endocyto- sis. Because the nanoparticles were $170 \mathrm{~nm}$ in diameter, the researchers conjectured that the nanoparticles could not be transported directly by organic anion-transporting polypeptides [171] and suggested that transporters on the basolateral membrane may have played an active role in nanoparticle uptake. A gene knockdown experiment with Hmgcr mRNA in Hepa1-6 cells demonstrated targeted delivery of DY-635-nanoparticle siRNA, with 75 and $60 \%$ decreases in mRNA levels after 16 and 24 $\mathrm{h}$, respectively. In vivo targeting showed that, following two injections ( $7 \mu \mathrm{g}$ NP per g body weight) via a venous port, a 70\% decrease in Hmgcr mRNA and a substantial decrease in plasma cholesterol were achieved. DY635-carrying nanoparticles increased plasma cholesterol with no other side effects, and this increase was substantially reduced by DY-635-functionalized delivery of siRNA in poly(lactic-co-glycolic acid) nanoparticles. The researchers suggested that this targeted delivery strategy can potentially be used for imaging and therapy of hepatic cancer.

Ki et al. developed a chitosan-based hybrid nanocomplex with high physical stability in the bloodstream. Hybrid nanocomplexes with a mean diameter of $<200 \mathrm{~nm}$ were prepared by combining survivin siRNA, protamine, lecithin, chitosan and tripolyphosphate (GP-L-CT) for systemic delivery of survivin siRNA [172]. The tumor targetability and antitumor efficacy of siRNA/nanoparticles were tested in a prostate cancer (PC-3 cells) xenograft mouse model by NIR fluorescence imaging and tumor growth monitoring. Chitosan-based nanoparticles have low cytotoxic effects, high biocompatibility, high mucoadhesiveness and high cell permeability, but they also have some weaknesses, such as low gene delivery efficiency in vivo.

To develop a more stable and efficient hybrid nanocomplex, the researchers generated a precomplex composed of siRNA and protamine and added lecithin, chitosan and tripolyphosphate to stabilize the formulation. Protamine binds to the lipophilic moiety in a phospholipid and improves nanoparticle stability $[173,174]$. Lecithin was added in culture medium with $50 \%$ fetal bovine serum. The results of a gel retardation assay showed that chitosan- $\mathrm{HCl}$ with a molecular weight of $150-400 \mathrm{kDa}$ and $95 \%$ deacetylation produced higher siRNA levels and lower survivin expression. The rate of cellular uptake (mean population percentages in P1 regions) for GP-L-CT complexes in PC-3 cells was $83.9 \%$, compared with $40.0 \%$ for Lipofectamine 2000. NIR fluorescence imaging at 2 and $5 \mathrm{~h}$ after intravenous injection ( $80 \mu \mathrm{g}$ siRNA per mouse) in a PC-3 tumor xenograft mouse model showed that the fluorescence intensity of Cy5.5-siRNA-carrying GP-LCT nanoparticles in the tumor region was higher than that of naked Cy5.5-siRNA or Cy5.5-siRNA-carrying 


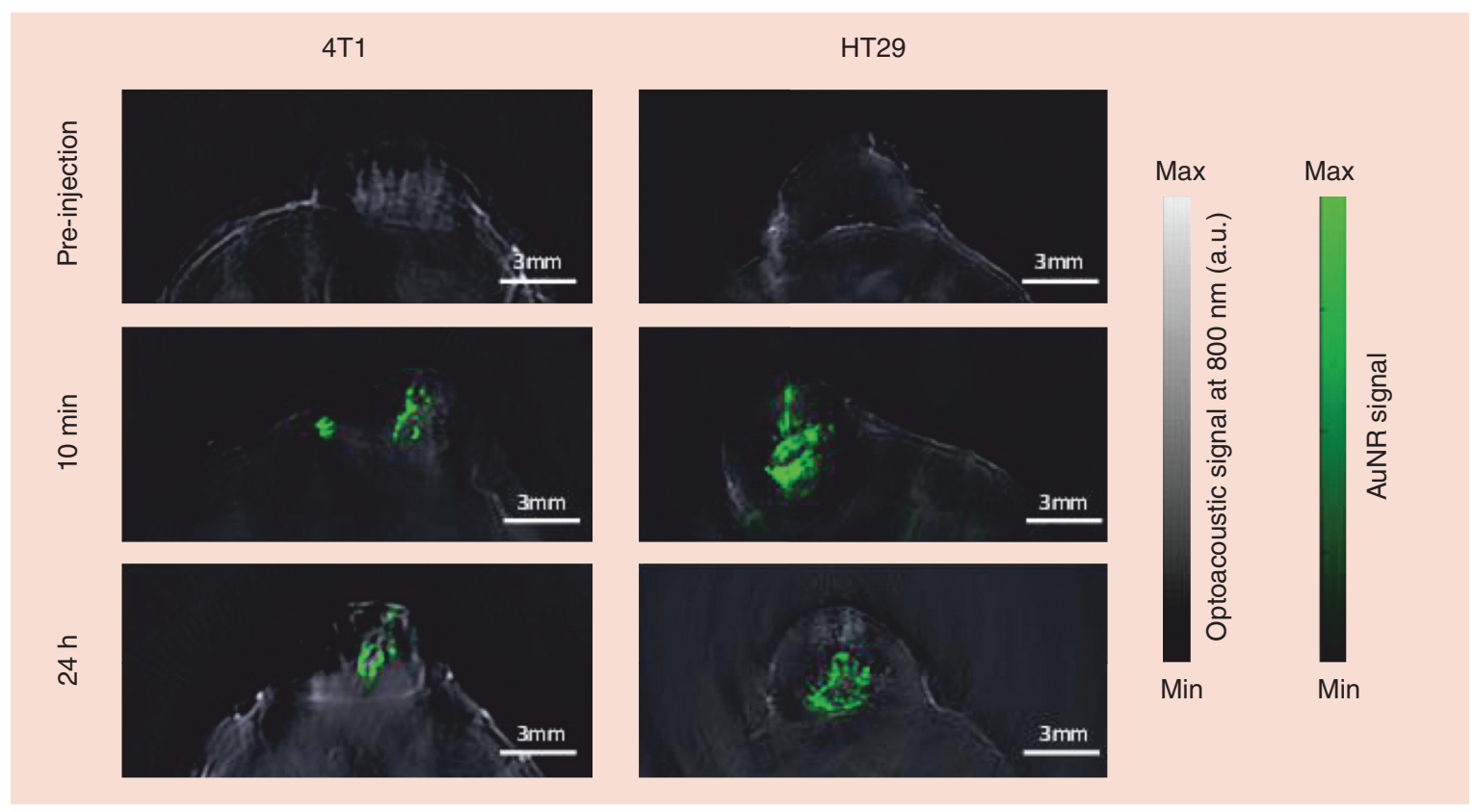

Figure 4. In vivo multispectral optoacoustic tomography transverse images showing multispectrally resolved NIRliposome-gold nanorod ${ }_{780}$ /PLK-1 siRNA complexes (green overlay) in 4T1 and HT29 cell tumors at the indicated time points.

Reprinted with permission from [146]. ( 2014 Royal Society of Chemistry.

Lipofectamine 2000. The nanoparticles were accumulated in the tumor region due to the enhanced permeability and retention effect [175]. In contrast to pore size in normal vasculature, which is $<10 \mathrm{~nm}$, tumor regions have wide fenestrations in neovasculature, with a pore size of 100-700 $\mathrm{nm}$ and defective lymphatic drainage [176]. After i.v. injection ( $40 \mu \mathrm{g}$ siRNA per mouse) the GP-L-CT nanoparticles inhibited tumor growth by $75.5 \%$ by day 18 .

Chen et al. developed a prostate-specific membrane antigen-targeted nanoplex platform for theranostic imaging of prostate cancer [85]. PSMA has been widely used as a specific target for prostate cancer treatment, and its expression is correlated with androgen insensitivity and tumor invasiveness [177-179]. The nanoplexes had a longitudinal size of $65 \mathrm{~nm}$ and a zeta potential of $1.6 \mathrm{mV}$. A Cy5.5-labeled poly-L-lysine (PLL) probe was used for multimodal imaging because of its emission in the NIR region $(680-900 \mathrm{~nm})$. Since autofluorescence and absorption by intrinsic chromophores are relatively low in this spectral region, Cy5.5 can be used effectively for in vivo optical imaging. The prodrug-activating bacterial cytosine deaminase (bCD) was cross-linked to a PEI-PLL copolymer to produce bCD-PLL-PEI. bCD converts the nontoxic prodrug 5 -fluorocytosine into the toxic 5-fluorouracil, which is detectable by 19F MR spectroscopy [180,181]. PLL was chosen as the linker between PEI and bCD to avoid the loss of activity by PEI and thus maintain bCD activity. bCD was active up to $48 \mathrm{~h}$ postinjection.
The researchers also tested the therapeutic functionality of this theranostic system by using the nanoplexes to downregulate choline kinase (Chk). Chk converts choline to phosphocholine, which is significantly upregulated in aggressive breast cancer cells and plays a critical role in tumor growth, invasion and metastasis [182,183]. MR spectroscopy or positron emission tomography can be used to track changes in choline metabolism. The siRNA was conjugated to the PEIPEG-cografted polymer through electrostatic interactions. To track the intracellular and in vivo distribution of the siRNA microscopically, the researchers conjugated rhodamine to PEI. For the targeting function, a urea-based PSMA-targeting moiety (2-(3- [1-carboxy-5- [7-(2,5-dioxopyrrolidin-1-yloxycarbonyl)heptanoylamino]pentyl]-ureido)pentanedioic acid) was used to conjugate maleimide-PEG-NH to PEI $[184,185]$. For in vivo tracking of the nanoplexes, $\left[{ }^{111} \mathrm{In}\right] 1,4,7,10$ tetraazacyclododecane-1,4,7,10-tetraacetic acid was conjugated to the PEI-PEG-cografted polymer to enable single-photon emission computed tomography. The images confirmed that PSMA increased the uptake rate, as evidenced by a significant difference between mice bearing PC3-PIP (PSMA-positive) tumors and mice bearing PC3-Flu (PSMA-negative) tumors (Figure 6). In vivo ${ }^{1} \mathrm{H}$ MR spectroscopy of PC3-PIP tumors $48 \mathrm{~h}$ after nanoplex injection (150 $\mathrm{mg} / \mathrm{kg}$ ) showed that total choline (free choline, phosphocholine and glycerophosphocholine) decreased to about $30 \%$ of pretreatment values. It had been previ- 

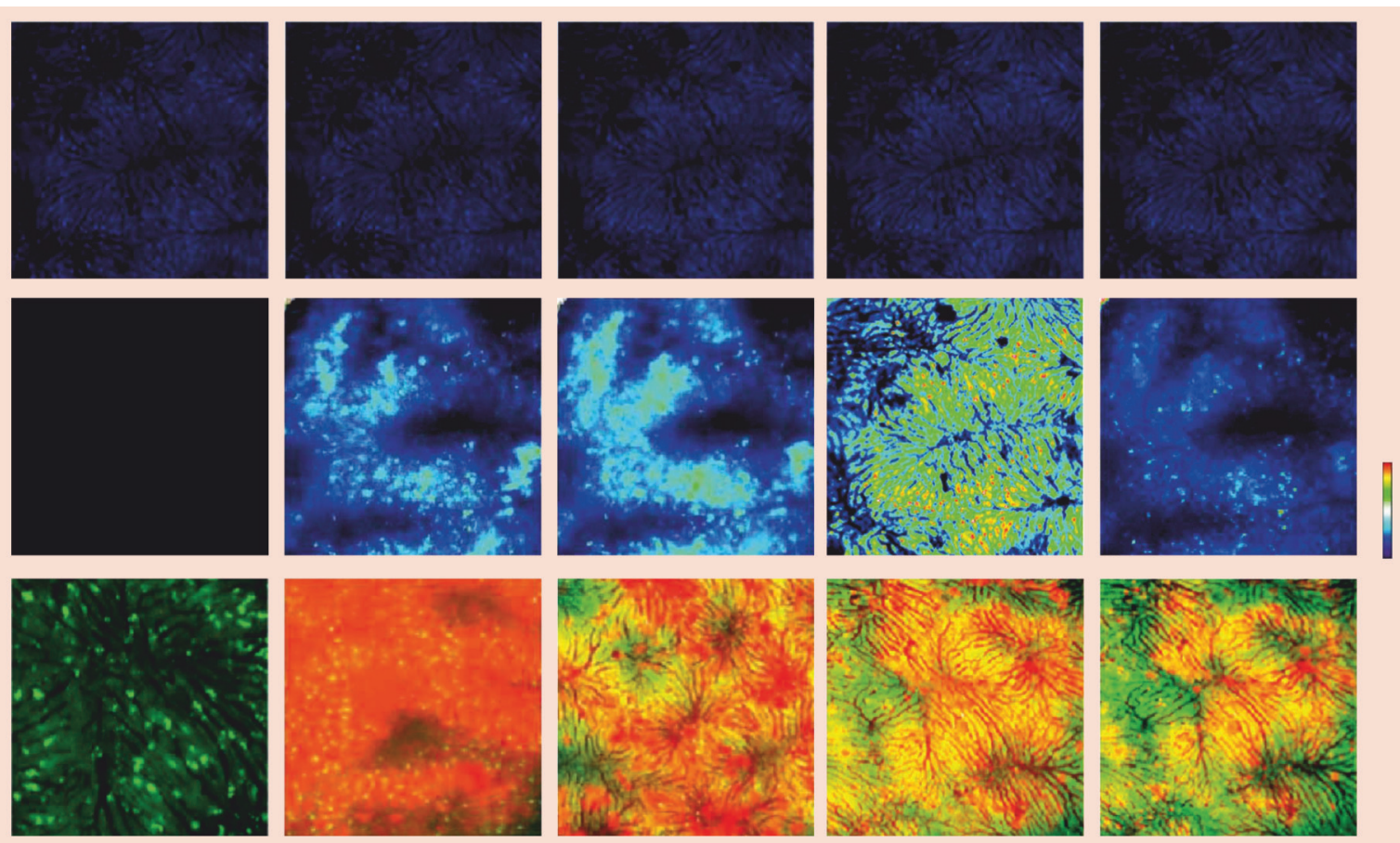

Figure 5. Intravital epifluorescence microscopy of acinar distribution of DY-635-labeled nanoparticles. The upper panels show background fluorescence in the liver (blue). The middle panels are heat maps (blue: low intensity, red: high intensity) of signal distribution, which is concentrated in the pericentral region of the liver lobule soon after injection of the nanoparticles and spreads toward the midzonal region and even the periportal region over time. The lower panels are corresponding false-color images of the association of DY-635 fluorescence (red) with liver parenchyma (green). Fluorescence is restricted to the vascular compartment 5 min after injection, and the yellow signal indicating colocalization of the dye with liver parenchyma increases over time. Scale bars: $100 \mathrm{~mm}$. Reprinted with permission from [147]. (C) 2014 Nature Publishing Group.

ously reported that tumor doubling time was reduced threefold with bCD only and sixfold with siRNA- and bCD-containing nanoplexes together with a single dose of 5-fluorocytosine [186].

To evaluate the toxicity of the nanoplex, alanine aminotransferase (ALT), aspartate aminotransferase (AST), creatinine and blood urea nitrogen measurements were performed to assess the hepatic and renal toxicity and no significant difference was observed in comparison to control group.

\section{Pros \& cons of oligonucleotide-based theranostic nanoparticles}

As with many other nanoparticle formulations, there are some important pros and cons related with oligonucleotide-based theranostic nanoparticles that are mentioned below.

\section{Pros}

- Oligonucleotides target the malfunctioning gene of interest or upregulated oncogenes inside the tumor directly, so they are more specific than conventional therapeutics.
- Using highly specific oligonucleotides eliminates the very common side effects and toxicities that are associated with conventional therapeutics.

- Using oligonucleotides facilitates and expedites the development of therapeutics for different therapeutic targets.

- Oligonucleotides are very small structures that can be easily functionalized and conjugated to theranostic nanoparticles.

- Theranostic nanoparticles can provide passive targeting to the tumor site and at the same time be tracked for their eventual destination and monitoring of the therapy.

- If they are finely designed they can provide researchers with highly specific imaging and therapeutic vehicles.

- They can assure the doctor or the patient that the therapy that is being applied worth continuing or should be aborted.

- Delivery of the therapeutics to the target site 
and their accumulation in the tumor site can be visualized temporally.

\section{Cons}

- Toxicity of nanoparticles such as QDs, magnetic nanoparticles, polymeric nanoparticles, etc. is one of the problems and if they are not modified they cannot enter to the clinic.

- Oligonucleotides have some off target effects and chemical modifications are needed to reduce the toxic effects associated with them.

- In order to deliver negatively charged oligonucleotides surface modifications of nanoparticles such as coating with cationic polymers or lipids are necessary which can cause major toxicity issues.

- Radioisotopes or fluorescent dyes which are used as imaging agents have some concerning toxicities that should be noticed.

- Nanoparticle size, targeting moiety and surface properties are some important factors that if not designed properly, can lead to the accumulation in wrong sites.

- Aggregation of nanoparticles or the stability problems of some nanoparticle formulations can decrease the efficiency of the therapy.

\section{Future perspective}

Each targeting strategy has advantages and disadvantages, and many have clinical applications. Combination strategies may improve the precision of drug delivery and pave the way for more effective personalized therapy. The definition of theranostics may need to be expanded to include targeting functionality in addition to imaging and therapy. Aptamers have shown great potential as targeting agents, and future research will need to identify new highly specific targets.

As new gene targets continue to emerge, incorporation of oligonucleotides in theranostic nanoparticles will facilitate more specific imaging and therapy. These systems need to maintain their stability and the stability of their oligonucleotide payload. Nanoparticle systems behave differently in vivo and in vitro, and formulations that show high stability in vitro may lose that stability or get eliminated by the reticuloendothelial system in vivo. Before a theranostic approach can be implemented in clinical practice, it needs to undergo comprehensive testing in animal models. In addition, in cases of tumor heterogeneity (distinct morphological and phenotypic profiles in a tumor), simultaneous targeting of different pathways may be necessary.
In order for oligonucleotide-based theranostics to enter to the clinic they should be able to be visualized with imaging modalities with high tissue penetration. Furthermore, there should be more focus on the toxicity of nanoparticles or imaging agents. Conventionally used imaging agents have some toxicity issues associated with them and safer alternatives should be used during theranostic approaches. Also, if theranostic nanoparticles such as magnetic nanoparticles, QDs etc. are going to be used, they should be designed in a way to minimize their toxicity. For instance, although magnetic nanoparticles can be used for imaging with MRI but there are some critical toxicity issues that need to be addressed before they could enter to the clinic.

\section{Conclusion}

The recent developments in theranostic applications using nanoparticles carrying highly specific oligonucleotides have aided early detection of malignancies and targeted therapy. Oligonucleotide-based therapeutics can target different cancer cell pathways, and the use of oligonucleotides in theranostic systems has
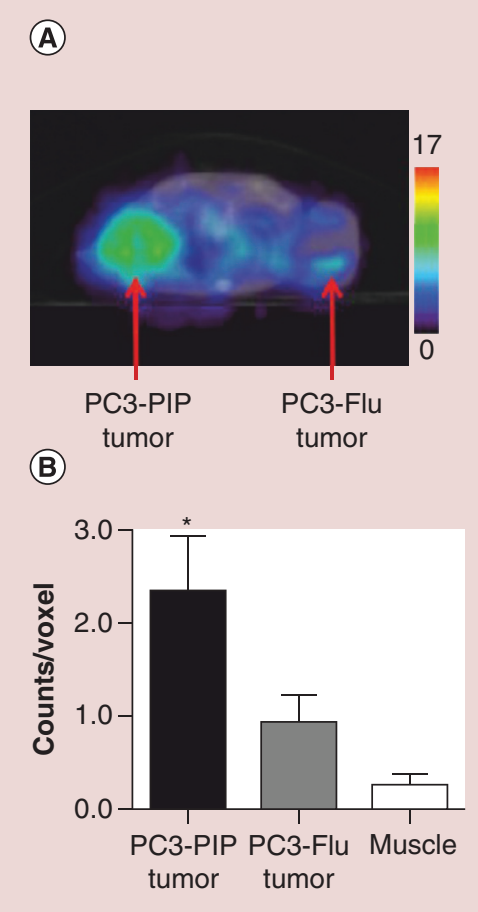

Figure 6. Effect of PSMA targeting on the uptake of nanoparticles. (A) Representative single-photon emission computed tomography images of an SCID mouse bearing PC3-PIP and PC3-Flu cell tumors, showing accumulation of radioactivity in the PC3-PIP tumor at 48 h. (B) Region-of-interest analysis of tumors and muscle, showing significant accumulation of radioactivity in PC3-PIP tumors $48 \mathrm{~h}$ postinjection. Reprinted with permission from [60]. () 2012 American Chemical Society. 
facilitated precise assessment of tumors before and after therapy. Newly discovered targeting moieties can act as magic bullets for targeted delivery of therapeutic agents. Perhaps in the near future, the radioactive or toxic chemicals currently used in cancer imaging and therapy will be replaced by magic-bullet theranostics, offering cancer cell-specific imaging and therapy and thus furthering the advancement of personalized medicine.
Financial \& competing interests disclosure

This study was supported by The Scientific and Technological Research Council of Turkey (TUBITAK) 2215 scholarship program. The authors have no other relevant affiliations or financial involvement with any organization or entity with a financial interest in or financial conflict with the subject matter or materials discussed in the manuscript apart from those disclosed.

No writing assistance was utilized in the production of this manuscript.

\section{Executive summary}

\section{Theranostic nanoparticles}

- Theranostic approach which is based on combined therapy and diagnosis can provide the early detection and targeted treatment of different cancer types, monitoring of the treatment progress, personalized cancer treatment.

- Nanoparticle-based theranostics avoid the disadvantages of conventional contrast agents and facilitate the detection of tumors smaller than $0.5 \mathrm{~cm}$ and discrimination between benign and cancerous tissues.

Oligonucleotides-based theranostics

- Oligonucleotide-based therapeutics such as small interfering RNA, microRNA and small hairpin RNA are highly specific targeted approaches that can be easily delivered by theranostic nanoparticulate systems and overcome their long lasting delivery problem.

- Targeted delivery of oligonucleotide-based theranostic nanoparticles can be achieved either by passive targeting or active targeting via ligands, antibodies, antibody fragments and aptamers.

Designing of the theranostic nanoparticles

- Imaging moieties and therapeutic oligonucleotides can be encapsulated inside the nanoparticles or conjugated on the nanoparticle surface. Targeting moieties are generally conjugated to the surface of nanoparticle.

- Inorganic nanoparticles such as superparamagnetic nanoparticles, quantum dots and gold nanoparticles are one of great candidates in theranostic approaches as they do not need any imaging moiety and can be easily imaged.

- As oligonucleotides are conjugated to the surface of inorganic nanoparticles so the surface of nanoparticles needs to be modified by cationic structures for electrostatic interaction. Polyvalent oligonucleotide/gold nanoparticle conjugates are one of promising approaches that do not contain any cationic structure and are robust gene delivery and imaging vehicles.

\section{References}

1 Khanna SC, Speiser P. Epoxy resin beads as a pharmaceutical dosage form. I. Method of preparation. J. Pharm. Sci. 58(9), 1114-1117 (1969).

2 Khanna SC, Jecklin T, Speiser P. Bead polymerization technique for sustained-release dosage form. J. Pharm. Sci. 59(5), 614-618 (1970).

3 Kreuter J. Nanoparticles-a historical perspective. Int. J. Pharm. 331(1), 1-10 (2007).

4 Bruchez M Jr, Moronne M, Gin P, Weiss S, Alivisatos AP. Semiconductor nanocrystals as fluorescent biological labels. Science 281(5385), 2013-2016 (1998).

5 Chan WC, Nie S. Quantum dot bioconjugates for ultrasensitive nonisotopic detection. Science 281(5385), 2016-2018 (1998).

6 Wang SP, Mamedova N, Kotov NA, Chen W, Studer $\mathrm{J}$. Antigen/antibody immunocomplex from CdTe nanoparticle bioconjugates. Nano Lett. 2(8), 817-822 (2002).
7 Edelstein RL, Tamanaha CR, Sheehan PE et al. The BARC biosensor applied to the detection of biological warfare agents. Biosens. Bioelectron. 14(10), 805-813 (2000).

8 Chung HJ, Castro CM, Im H, Lee H, Weissleder R. A magneto-DNA nanoparticle system for rapid detection and phenotyping of bacteria. Nat. Nanotechnol. 8(5), 369-375 (2013).

$9 \quad$ Mah C, Fraites TJ Jr., Zolotukhin I et al. Improved method of recombinant AAV2 delivery for systemic targeted gene therapy. Mol. Ther. 6(1), 106-112 (2002).

10 Pantarotto D, Partidos CD, Hoebeke J et al. Immunization with peptide-functionalized carbon nanotubes enhances virus-specific neutralizing antibody responses. Chem. Biol. 10(10), 961-966 (2003).

11 Kirtane AR, Panyam J. Polymer nanoparticles: weighing up gene delivery. Nat. Nanotechnol. 8(11), 805-806 (2013).

12 Nam JM, Thaxton CS, Mirkin CA. Nanoparticle-based biobar codes for the ultrasensitive detection of proteins. Science 301(5641), 1884-1886 (2003). 
13 Monroe MR, Daaboul GG, Tuysuzoglu A, Lopez CA, Little FF, Unlu MS. Single nanoparticle detection for multiplexed protein diagnostics with attomolar sensitivity in serum and unprocessed whole blood. Anal. Chem. 85(7), 3698-3706 (2013).

14 Mahtab R, Rogers JP, Murphy CJ. Protein-sized quantumdot luminescence can distinguish between straight, bent, and kinked oligonucleotides. J. Am. Chem. Soc. 117(35), 9099-9100 (1995).

15 Bai X, Wu JJ, Han XG, Deng ZX. Probing DNA's interstrand orientation with gold nanoparticles. Anal. Chem. 83(13), 5067-5072 (2011).

16 Ma J, Wong HF, Kong LB, Peng KW. Biomimetic processing of nanocrystallite bioactive apatite coating on titanium. Nanotechnology 14(6), 619-623 (2003).

17 Ito A, Kamihira M. Tissue engineering using magnetite nanoparticles. Prog. Mol. Biol. Transl. Sci. 104, 355-395 (2011).

18 Shinkai M, Yanase M, Suzuki M et al. Intracellular hyperthermia for cancer using magnetite cationic liposomes. J. Magn. Magn. Mater. 194(1), 176-184 (1999).

19 Tamarov KP, Osminkina LA, Zinovyev SV et al. Radio frequency radiation-induced hyperthermia using $\mathrm{Si}$ nanoparticle-based sensitizers for mild cancer therapy. Sci. Rep. 4, 7034 (2014).

20 Molday RS, Mackenzie D. Immunospecific ferromagnetic iron-dextran reagents for the labeling and magnetic separation of cells. J. Immunol. Methods 52(3), 353-367 (1982).

21 Mettler E, Trenkler A, Feilen PJ et al. Magnetic separation of encapsulated islet cells labeled with superparamagnetic iron oxide nano particles. Xenotransplantation 20(4), 219-226 (2013).

22 Weissleder R, Elizondo G, Wittenberg J, Rabito CA, Bengele $\mathrm{HH}$, Josephson L. Ultrasmall superparamagnetic iron oxide: characterization of a new class of contrast agents for MR imaging. Radiology 175(2), 489-493 (1990).

23 Oghabian MA, Gharehaghaji N, Amirmohseni S, Khoei S, Guiti M. Detection sensitivity of lymph nodes of various sizes using USPIO nanoparticles in magnetic resonance imaging. Nanomedicine 6(3), 496-499 (2010).

24 Bardhan R, Lal S, Joshi A, Halas NJ. Theranostic nanoshells: from probe design to imaging and treatment of cancer. Acc. Chem. Res. 44(10), 936-946 (2011).

25 Cole AJ, Yang VC, David AE. Cancer theranostics: the rise of targeted magnetic nanoparticles. Trends Biotechnol. 29(7), 323-332 (2011).

26 Lim EK, Kim T, Paik S, Haam S, Huh YM, Lee K. Nanomaterials for theranostics: recent advances and future challenges. Chem. Rev. 115(1), 327-394 (2015).

27 Rusinek H, Naidich DP, Mcguinness G et al. Pulmonary nodule detection: low-dose versus conventional CT. Radiology 209(1), 243-249 (1998).

28 Popovtzer R, Agrawal A, Kotov NA et al. Targeted gold nanoparticles enable molecular CT imaging of cancer. Nano Lett. 8(12), 4593-4596 (2008).
29 Al-Nahhas A, Win Z, Szyszko T et al. Gallium-68 PET: a new frontier in receptor cancer imaging. Anticancer Res. 27(6B), 4087-4094 (2007).

30 Nanni C, Rubello D, Fanti S et al. Role of 18F-FDGPET and PET/CT imaging in thyroid cancer. Biomed. Pharmacother. 60 (8), 409-413 (2006).

31 Zolata H, Abbasi Davani F, Afarideh H. Synthesis, characterization and theranostic evaluation of Indium-111 labeled multifunctional superparamagnetic iron oxide nanoparticles. Nucl. Med. Biol. 42(2), 164-170 (2015).

32 Maggioni D, Arosio P, Orsini F et al. Superparamagnetic iron oxide nanoparticles stabilized by a poly(amidoamine)rhenium complex as potential theranostic probe. Dalton Trans. 43(3), 1172-1183 (2014).

33 Ho YP, Leong KW. Quantum dot-based theranostics. Nanoscale 2(1), 60-68 (2010).

34 Tian BW, Al-Jamal WT, Kostarelos K. The engineering of doxorubicin-loaded liposome-quantum dot hybrids for cancer theranostics. Chinese Phys. B 23(8), 087805 1-087805-4 (2014).

35 Li J, Gupta S, Li C. Research perspectives: gold nanoparticles in cancer theranostics. Quant. Imaging Med. Surg. 3(6), 284-291 (2013).

36 Heo DN, Yang DH, Moon HJ et al. Gold nanoparticles surface-functionalized with paclitaxel drug and biotin receptor as theranostic agents for cancer therapy. Biomaterials 33(3), 856-866 (2012).

37 Lusic H, Grinstaff MW. X-ray-computed tomography contrast agents. Chem. Rev. 113(3), 1641-1666 (2013).

38 Malumbres M, Barbacid M. RAS oncogenes: the first 30 years. Nat. Rev. Cancer 3(6), 459-465 (2003).

39 Petersen NS, Mclaughlin CS, Nierlich DP. Half life of yeast messenger RNA. Nature 260(5546), 70-72 (1976).

40 Dean NM, Bennett CF. Antisense oligonucleotide-based therapeutics for cancer. Oncogene 22(56), 9087-9096 (2003).

41 Akar U, Ozpolat B, Mehta K et al. Targeting p70S6K prevented lung metastasis in a breast cancer xenograft model. Mol. Cancer Ther. 9(5), 1180-1187 (2010).

42 Ozpolat B, Sood AK, Lopez-Berestein G. Liposomal siRNA nanocarriers for cancer therapy. Adv. Drug Deliv. Rev. 66, 110-116 (2014).

43 Kumar R, Shin WS, Sunwoo K et al. Small conjugate-based theranostic agents: an encouraging approach for cancer therapy. Chem. Soc. Rev. 44(19), 6670-6683 (2015).

44 Lim EK, Kim T, Paik S, Haam S, Huh YM, Lee K. Nanomaterials for theranostics: recent advances and future challenges. Chem. Rev. 115(1), 327-394 (2015).

45 Jokerst JV, Gambhir SS. Molecular imaging with theranostic nanoparticles. Acc. Chem. Res. 44(10), 1050-1060 (2011).

46 Wang J, Lu Z, Wientjes MG, Au JL. Delivery of siRNA therapeutics: barriers and carriers. AAPS J. 12(4), 492-503 (2010).

47 Whitehead KA, Langer R, Anderson DG. Knocking down barriers: advances in siRNA delivery. Nat. Rev. Drug Discov. 8(2), 129-138 (2009). 
48 Corot C, Warlin D. Superparamagnetic iron oxide nanoparticles for MRI: contrast media pharmaceutical company R\&D perspective. Wiley Interdiscip. Rev. Nanomed. Nanobiotechnol. 5(5), 411-422 (2013).

49 Xi D, Dong S, Meng XX, Lu QH, Meng LJ, Ye J. Gold nanoparticles as computerized tomography (CT) contrast agents. RSC Adv. 2(33), 12515-12524 (2012).

50 Kim S, Lim YT, Soltesz EG et al. Near-infrared fluorescent type II quantum dots for sentinel lymph node mapping. Nat. Biotechnol. 22(1), 93-97 (2004).

51 De Barros AB, Tsourkas A, Saboury B, Cardoso VN, Alavi A. Emerging role of radiolabeled nanoparticles as an effective diagnostic technique. EJNMMI Res. 2(1), 39 (2012).

$52 \mathrm{Li}$ L, Shen Y. Overcoming obstacles to develop effective and safe siRNA therapeutics. Expert Opin. Biol. Ther. 9(5), 609-619 (2009).

53 Ashley CE, Carnes EC, Phillips GK et al. The targeted delivery of multicomponent cargos to cancer cells by nanoporous particle-supported lipid bilayers. Nat. Mater. 10(5), 389-397 (2011).

54 Summerton J. Morpholino antisense oligomers: the case for an RNase H-independent structural type. Biochim. Biophys. Acta 1489(1), 141-158 (1999).

55 Corey DR, Abrams JM. Morpholino antisense oligonucleotides: tools for investigating vertebrate development. Genome Biol. 2(5), REVIEWS1015 (2001).

56 Inoue S, Patil R, Portilla-Arias J et al. Nanobiopolymer for direct targeting and inhibition of EGFR expression in triple negative breast cancer. PLoS One 7(2), e31070 (2012).

57 Sekhon HS, London CA, Sekhon M, Iversen PL, Devi GR. c-MYC antisense phosphosphorodiamidate morpholino oligomer inhibits lung metastasis in a murine tumor model. Lung Cancer 60 (3), 347-354 (2008).

58 Guo W, Chen W, Yu W, Huang W, Deng W. Small interfering RNA-based molecular therapy of cancers. Chin. J. Cancer 32(9), 488-493 (2013).

59 Ye QF, Zhang YC, Peng XQ, Long Z, Ming YZ, He LY. Silencing Notch-1 induces apoptosis and increases the chemosensitivity of prostate cancer cells to docetaxel through Bcl-2 and Bax. Oncol. Lett. 3(4), 879-884 (2012).

60 Tekedereli I, Alpay SN, Tavares CD et al. Targeted silencing of elongation factor 2 kinase suppresses growth and sensitizes tumors to doxorubicin in an orthotopic model of breast cancer. PLoS One 7(7), e41171 (2012).

61 Balkwill F. Cancer and the chemokine network. Nat. Rev. Cancer 4(7), 540-550 (2004).

62 Jiang K, Li J, Yin J et al. Targeted delivery of CXCR4-siRNA by scFv for HER2 (+) breast cancer therapy. Biomaterials 59 , 77-87 (2015).

63 Ashour AA, Abdel-Aziz AA, Mansour AM, Alpay SN, Huo L, Ozpolat B. Targeting elongation factor-2 kinase (eEF-2K) induces apoptosis in human pancreatic cancer cells. Apoptosis 19(1), 241-258 (2014).

64 Yin T, Wang L, Yin L, Zhou J, Huo M. Co-delivery of hydrophobic paclitaxel and hydrophilic AURKA specific siRNA by redox-sensitive micelles for effective treatment of breast cancer. Biomaterials 61, 10-25 (2015).
65 Parvani JG, Gujrati MD, Mack MA, Schiemann WP, Lu ZR. Silencing beta 3 Integrin by targeted ECO/siRNA nanoparticles inhibits EMT and metastasis of triplenegative breast cancer. Cancer Res. 75(11), 2316-2325 (2015).

66 Gao Y, Wu H, He D, Hu X, Li Y. Downregulation of BCL11A by siRNA induces apoptosis in B lymphoma cell lines. Biomed. Rep. 1(1), 47-52 (2013).

67 Faltus T, Yuan J, Zimmer B et al. Silencing of the HER2/neu gene by siRNA inhibits proliferation and induces apoptosis in HER2/neu-overexpressing breast cancer cells. Neoplasia 6(6), 786-795 (2004).

68 Braicu C, Pileczki V, Pop L et al. Dual targeted therapy with p53 siRNA and epigallocatechingallate in a triple negative breast cancer cell model. PLoS One 10(4), e0120936 (2015).

69 Cengiz BB, Asik MD, Kara G, Turk M, Denkbas EB. Therapeutic potential of inhibiting ABCE1 and eRF3 genes via siRNA strategy using chitosan nanoparticles in breast cancer cells. J. Nanopart. Res. 17(4), 168 (2015).

70 Reischl D, Zimmer A. Drug delivery of siRNA therapeutics: potentials and limits of nanosystems. Nanomedicine 5(1), 8-20 (2009).

71 Winter J, Jung S, Keller S, Gregory RI, Diederichs S. Many roads to maturity: microRNA biogenesis pathways and their regulation. Nat. Cell Biol. 11(3), 228-234 (2009).

72 Gandhi NS, Tekade RK, Chougule MB. Nanocarrier mediated delivery of siRNA/miRNA in combination with chemotherapeutic agents for cancer therapy: current progress and advances. J. Control. Release 194, 238-256 (2014).

73 Cai Y, Yu X, Hu S, Yu J. A brief review on the mechanisms of miRNA regulation. Genomics Proteom. Bioinform. 7(4), 147-154 (2009).

74 Diaz MR, Vivas-Mejia PE. Nanoparticles as drug delivery systems in cancer medicine: emphasis on RNAi-containing nanoliposomes. Pharmaceuticals (Basel) 6(11), 1361-1380 (2013).

75 Taube JH, Malouf GG, Lu E et al. Epigenetic silencing of microRNA-203 is required for EMT and cancer stem cell properties. Sci. Rep. 3, 2687 (2013).

76 Rao DD, Vorhies JS, Senzer N, Nemunaitis J. siRNA vs. shRNA: similarities and differences. Adv. Drug Deliv. Rev. 61(9), 746-759 (2009).

77 Cullen BR. RNAi the natural way. Nat. Genet. 37(11), 1163-1165 (2005).

78 Lee Y, Ahn C, Han J et al. The nuclear RNase III Drosha initiates microRNA processing. Nature 425 (6956), 415-419 (2003).

79 Zhang HD, Kolb FA, Brondani V, Billy E, Filipowicz W. Human Dicer preferentially cleaves dsRNAs at their termini without a requirement for ATP. EMBO J. 21(21), 5875-5885 (2002).

80 Lee Y, Jeon K, Lee JT, Kim S, Kim VN. MicroRNA maturation: stepwise processing and subcellular localization. EMBO J. 21(17), 4663-4670 (2002).

81 Cullen BR. Transcription and processing of human microRNA precursors. Mol. Cell 16(6), 861-865 (2004). 
in Y, Macara IG, Cullen BR. Exportin-5 mediates the nuclear export of pre-microRNAs and short hairpin RNAs. Genes Dev. 17(24), 3011-3016 (2003).

Lund E, Guttinger S, Calado A, Dahlberg JE, Kutay U. Nuclear export of microRNA precursors. Science 303(5654), 95-98 (2004).

84 Lee YS, Nakahara K, Pham JW et al. Distinct roles for Drosophila Dicer-1 and Dicer-2 in the siRNA/miRNA silencing pathways. Cell 117(1), 69-81 (2004).

Chen Z, Penet MF, Nimmagadda $S$ et al. PSMA-targeted theranostic nanoplex for prostate cancer therapy. ACS Nano 6(9), 7752-7762 (2012).

86 Ramos J, Rege K. Poly(aminoether)-gold nanorod assemblies for shRNA plasmid-induced gene silencing. Mol. Pharm. 10(11), 4107-4119 (2013).

87 Lambeth LS, Van Hateren NJ, Wilson SA, Nair V. A direct comparison of strategies for combinatorial RNA interference. BMC Mol. Biol. 11, 77 (2010). expressions in a single plasmid vector improve RNAi against the XPA gene. Biochem. Biophys. Res. Commun. 370(2), 301-305 (2008).

Motegi Y, Katayama K, Sakurai F et al. An effective geneknockdown using multiple shRNA-expressing adenovirus vectors. J. Control. Release 153(2), 149-153 (2011).

90 Yu JY, Taylor J, Deruiter SL, Vojtek AB, Turner DL. Simultaneous inhibition of GSK3alpha and GSK3beta using hairpin siRNA expression vectors. Mol. Ther. 7(2), 228-236 (2003).

91 Mcintyre GJ, Fanning GC. Design and cloning strategies for constructing shRNA expression vectors. BMC Biotechnol. 6, 1 (2006).

92 Miyagishi M, Sumimoto H, Miyoshi H, Kawakami Y, Taira K. Optimization of an siRNA-expression system with an improved hairpin and its significant suppressive effects in mammalian cells. J. Gene Med. 6(7), 715-723 (2004).

93 Schally AV, Nagy A. Chemotherapy targeted to cancers through tumoral hormone receptors. Trends Endocrinol. Metab. 15(7), 300-310 (2004).

94 Schally AV, Nagy A. Cancer chemotherapy based on targeting of cytotoxic peptide conjugates to their receptors on tumors. Eur. J. Endocrinol. 141(1), 1-14 (1999).

95 Bazak R, Houri M, Achy SE, Hussein W, Refaat T. Passive targeting of nanoparticles to cancer: a comprehensive review of the literature. Mol. Clin. Oncol. 2(6), 904-908 (2014). cells. Biochim. Biophys. Acta 1269(3), 205-214 (1995). schemes for nanoparticle systems in cancer therapeutics. $A d v$. Drug Deliv. Rev. 60(15), 1615-1626 (2008). microenvironment: passive and active tumor targeting of nanocarriers for anti-cancer drug delivery. J. Control. Release 148(2), 135-146 (2010).

Bazak R, Houri M, El Achy S, Kamel S, Refaat T. Cancer active targeting by nanoparticles: a comprehensive review of literature. J. Cancer Res. Clin. Oncol. 141(5), 769-784 (2015).
100 Talekar M, Kendall J, Denny W, Garg S. Targeting of nanoparticles in cancer: drug delivery and diagnostics. Anticancer Drugs 22(10), 949-962 (2011).

101 Hilgenbrink AR, Low PS. Folate receptor-mediated drug targeting: from therapeutics to diagnostics. J. Pharm. Sci. 94(10), 2135-2146 (2005).

102 Yu B, Tai HC, Xue W, Lee LJ, Lee RJ. Receptor-targeted nanocarriers for therapeutic delivery to cancer. Mol. Membr. Biol. 27(7), 286-298 (2010).

103 Steinhauser I, Spankuch B, Strebhardt K, Langer K. Trastuzumab-modified nanoparticles: optimisation of preparation and uptake in cancer cells. Biomaterials 27(28), 4975-4983 (2006).

104 Yu MK, Kim D, Lee IH, So JS, Jeong YY, Jon S. Imageguided prostate cancer therapy using aptamer-functionalized thermally cross-linked superparamagnetic iron oxide nanoparticles. Small 7(15), 2241-2249 (2011).

105 Wartlick H, Michaelis K, Balthasar S, Strebhardt K, Kreuter J, Langer K. Highly specific HER2-mediated cellular uptake of antibody-modified nanoparticles in tumour cells. J. Drug Target. 12(7), 461-471 (2004).

106 Dilnawaz F, Singh A, Mohanty C, Sahoo SK. Dual drug loaded superparamagnetic iron oxide nanoparticles for targeted cancer therapy. Biomaterials 31(13), 3694-3706 (2010).

107 Glazer ES, Massey KL, Zhu C, Curley SA. Pancreatic carcinoma cells are susceptible to noninvasive radio frequency fields after treatment with targeted gold nanoparticles. Surgery 148(2), 319-324 (2010).

108 Cherukuri P, Curley SA. Use of nanoparticles for targeted, noninvasive thermal destruction of malignant cells. Methods Mol. Biol. 624, 359-373 (2010).

109 Ulbrich K, Hekmatara T, Herbert E, Kreuter J. Transferrinand transferrin-receptor-antibody-modified nanoparticles enable drug delivery across the blood-brain barrier (BBB). Eur. J. Pharm. Biopharm. 71(2), 251-256 (2009).

110 Gosk S, Vermehren C, Storm G, Moos T. Targeting antitransferrin receptor antibody (OX26) and OX26-conjugated liposomes to brain capillary endothelial cells using in situ perfusion. J. Cereb. Blood Flow Metab. 24(11), 1193-1204 (2004).

111 Bisker G, Yeheskely-Hayon D, Minai L, Yelin D. Controlled release of Rituximab from gold nanoparticles for phototherapy of malignant cells. J. Control. Release 162(2), 303-309 (2012).

112 Serda RE, Adolphi NL, Bisoffi M, Sillerud LO. Targeting and cellular trafficking of magnetic nanoparticles for prostate cancer imaging. Mol. Imaging 6(4), 277-288 (2007).

113 Taylor RM, Huber DL, Monson TC, Ali AM, Bisoff M, Sillerud LO. Multifunctional iron platinum stealth immunomicelles: targeted detection of human prostate cancer cells using both fluorescence and magnetic resonance imaging. J. Nanopart. Res. 13(10), 4717-4729 (2011).

114 Sugano M, Egilmez NK, Yokota SJ et al. Antibody targeting of doxorubicin-loaded liposomes suppresses the growth and metastatic spread of established human lung tumor xenografts in severe combined immunodeficient mice. Cancer Res. 60(24), 6942-6949 (2000). 
115 Brignole C, Marimpietri D, Gambini C, Allen TM, Ponzoni M, Pastorino F. Development of Fab' fragments of anti-GD(2) immunoliposomes entrapping doxorubicin for experimental therapy of human neuroblastoma. Cancer Lett. 197(1), 199-204 (2003).

116 Marty C, Langer-Machova Z, Sigrist S, Schott H, Schwendener RA, Ballmer-Hofer K. Isolation and characterization of a $\mathrm{scFv}$ antibody specific for tumor endothelial marker 1 (TEM1), a new reagent for targeted tumor therapy. Cancer Lett. 235(2), 298-308 (2006).

117 Lu RM, Chang YL, Chen MS, Wu HC. Single chain anti-cMet antibody conjugated nanoparticles for in vivo tumortargeted imaging and drug delivery. Biomaterials 32(12), 3265-3274 (2011).

118 Wang AZ, Gu F, Zhang L et al. Biofunctionalized targeted nanoparticles for therapeutic applications. Expert Opin. Biol. Ther. 8(8), 1063-1070 (2008).

119 Ni X, Castanares M, Mukherjee A, Lupold SE. Nucleic acid aptamers: clinical applications and promising new horizons. Curr. Med. Chem. 18(27), 4206-4214 (2011).

120 Chiu TC, Huang CC. Aptamer-functionalized nanobiosensors. Sensors (Basel) 9(12), 10356-10388 (2009).

121 Zhang Y, Hong H, Cai W. Tumor-targeted drug delivery with aptamers. Curr. Med. Chem. 18(27), 4185-4194 (2011).

122 Lee JH, Yigit MV, Mazumdar D, Lu Y. Molecular diagnostic and drug delivery agents based on aptamer-nanomaterial conjugates. Adv. Drug Deliv. Rev. 62 (6), 592-605 (2010).

123 Liss M, Petersen B, Wolf H, Prohaska E. An aptamerbased quartz crystal protein biosensor. Anal. Chem. 74(17), 4488-4495 (2002).

124 Farokhzad OC, Jon S, Khademhosseini A, Tran TN, Lavan DA, Langer R. Nanoparticle-aptamer bioconjugates: a new approach for targeting prostate cancer cells. Cancer Res. 64(21), 7668-7672 (2004).

125 Bagalkot V, Zhang L, Levy-Nissenbaum E et al. Quantum dot-aptamer conjugates for synchronous cancer imaging, therapy, and sensing of drug delivery based on bi-fluorescence resonance energy transfer. Nano Lett. 7(10), 3065-3070 (2007).

126 Hwang Do W, Ko HY, Lee JH et al. A nucleolin-targeted multimodal nanoparticle imaging probe for tracking cancer cells using an aptamer. J. Nucl. Med. 51(1), 98-105 (2010).

127 Yu C, Hu Y, Duan J et al. Novel aptamer-nanoparticle bioconjugates enhances delivery of anticancer drug to MUC1-positive cancer cells in vitro. PLoS One 6(9), e24077 (2011).

128 Zhao N, Bagaria HG, Wong MS, Zu Y. A nanocomplex that is both tumor cell-selective and cancer gene-specific for anaplastic large cell lymphoma. J. Nanobiotechnol. 9, 2 (2011).

129 Huang YF, Chang HT, Tan W. Cancer cell targeting using multiple aptamers conjugated on nanorods. Anal. Chem. 80(3), 567-572 (2008).

130 Zhao F, Yin H, Zhang Z, Li J. Folic acid modified cationic gamma-cyclodextrin-oligoethylenimine star polymer with bioreducible disulfide linker for efficient targeted gene delivery. Biomacromolecules 14(2), 476-484 (2013).
131 Patnaik S, Gupta KC. Novel polyethylenimine-derived nanoparticles for in vivo gene delivery. Expert Opin. Drug Deliv. 10(2), 215-228 (2013).

132 Guo S, Huang Y, Jiang Q et al. Enhanced gene delivery and siRNA silencing by gold nanoparticles coated with chargereversal polyelectrolyte. ACS Nano 4(9), 5505-5511 (2010).

133 Barua S, Ramos J, Potta T et al. Discovery of cationic polymers for non-viral gene delivery using combinatorial approaches. Comb. Chem. High Throughput Screen. 14(10), 908-924 (2011).

134 Giljohann DA, Seferos DS, Prigodich AE, Patel PC, Mirkin CA. Gene regulation with polyvalent siRNAnanoparticle conjugates. J. Am. Chem. Soc. 131(6), 2072-2073 (2009).

135 Joo WD, Visintin I, Mor G. Targeted cancer therapy-are the days of systemic chemotherapy numbered? Maturitas 76(4), 308-314 (2013).

136 Bahmani B, Guerrero Y, Bacon D, Kundra V, Vullev VI, Anvari B. Functionalized polymeric nanoparticles loaded with indocyanine green as theranostic materials for targeted molecular near infrared fluorescence imaging and photothermal destruction of ovarian cancer cells. Lasers Surg. Med. 46(7), 582-592 (2014).

137 Swierczewska M, Lee S, Chen X. Inorganic nanoparticles for multimodal molecular imaging. Mol. Imaging 10(1), 3-16 (2011).

138 Bishop CJ, Tzeng SY, Green JJ. Degradable polymer-coated gold nanoparticles for co-delivery of DNA and siRNA. Acta Biomater. 11, 393-403 (2015).

139 Boussif O, Lezoualch F, Zanta MA et al. A versatile vector for gene and oligonucleotide transfer into cells in culture and in-vivo - polyethylenimine. Proc. Natl Acad. Sci. USA 92(16), 7297-7301 (1995).

140 Sunshine JC, Peng DY, Green JJ. Uptake and transfection with polymeric nanoparticles are dependent on polymer end-group structure, but largely independent of nanoparticle physical and chemical properties. Mol. Pharm. 9(11), 3375-3383 (2012).

141 Li D, Tang X, Pulli B et al. Theranostic nanoparticles based on bioreducible polyethylenimine-coated iron oxide for reduction-responsive gene delivery and magnetic resonance imaging. Int. J. Nanomed. 9, 3347-3361 (2014).

142 Lin C, Zhong ZY, Lok MC et al. Novel bioreducible poly(amido amine)s for highly efficient gene delivery. Bioconj. Chem. 18(1), 138-145 (2007).

143 Lin C, Blaauboer CJ, Timoneda MM et al. Bioreducible poly(amido amine)s with oligoamine side chains: synthesis, characterization, and structural effects on gene delivery. J. Control. Release 126(2), 166-174 (2008).

144 Xia W, Lin C. Bioreducible polymer-delivered siRNA targeting human telomerase reverse transcriptase for human cancer gene therapy. Ther. Deliv. 3(4), 439-442 (2012).

145 Morin GB. The human telomere terminal transferase enzyme is a ribonucleoprotein that synthesizes TTAGGG repeats. Cell 59(3), 521-529 (1989).

146 Shay JW, Zou Y, Hiyama E, Wright WE. Telomerase and cancer. Hum. Mol. Genet. 10(7), 677-685 (2001). 
147 Philippi C, Loretz B, Schaefer UF, Lehr CM. Telomerase as an emerging target to fight cancer-opportunities and challenges for nanomedicine. J. Control. Release 146(2), 228-240 (2010).

148 Zhu D, Liu F, Ma L, Liu D, Wang Z. Nanoparticle-based systems for t1-weighted magnetic resonance imaging contrast agents. Int. J. Mol. Sci. 14(5), 10591-10607 (2013).

149 Cho YS, Lee GY, Sajja HK et al. Targeted delivery of siRNA-generating DNA nanocassettes using multifunctional nanoparticles. Small 9(11), 1964-1973 (2013).

150 Appella E, Robinson EA, Ullrich SJ et al. The receptorbinding sequence of urokinase. A biological function for the growth-factor module of proteases. J. Biol. Chem. 262(10), 4437-4440 (1987).

151 Nielsen BS, Rank F, Illemann M, Lund LR, Dano K. Stromal cells associated with early invasive foci in human mammary ductal carcinoma in situ coexpress urokinase and urokinase receptor. Int. J. Cancer 120(10), 2086-2095 (2007).

152 Blasi F, Carmeliet P. uPAR: a versatile signalling orchestrator. Nat. Rev. Mol. Cell Biol. 3(12), 932-943 (2002).

153 Pyke C, Graem N, Ralfkiaer E et al. Receptor for urokinase is present in tumor-associated macrophages in ductal breast carcinoma. Cancer Res. 53(8), 1911-1915 (1993).

154 Dohi T, Okada K, Xia F et al. An IAP-IAP complex inhibits apoptosis. J. Biol. Chem. 279(33), 34087-34090 (2004).

155 Li T, Shen X, Chen Y et al. Polyetherimide-grafted Fe(3) $\mathrm{O}(4) @ \mathrm{SiO}_{2}(2)$ nanoparticles as theranostic agents for simultaneous VEGF siRNA delivery and magnetic resonance cell imaging. Int. J. Nanomed. 10, 4279-4291 (2015).

156 Lee JH, Lee K, Moon SH, Lee Y, Park TG, Cheon J. All-in-one target-cell-specific magnetic nanoparticles for simultaneous molecular imaging and siRNA delivery. Angew. Chem. Int. Ed. Engl. 48(23), 4174-4179 (2009).

157 Arap W, Pasqualini R, Ruoslahti E. Cancer treatment by targeted drug delivery to tumor vasculature in a mouse model. Science 279(5349), 377-380 (1998).

158 Jung J, Solanki A, Memoli KA et al. Selective inhibition of human brain tumor cells through multifunctional quantumdot-based siRNA delivery. Angew. Chem. Int. Ed. Engl. 49(1), 103-107 (2010).

159 Durr NJ, Larson T, Smith DK, Korgel BA, Sokolov K, BenYakar A. Two-photon luminescence imaging of cancer cells using molecularly targeted gold nanorods. Nano Lett. 7(4), 941-945 (2007).

160 Li JL, Gu M. Surface plasmonic gold nanorods for enhanced two-photon microscopic imaging and apoptosis induction of cancer cells. Biomaterials 31(36), 9492-9498 (2010).

161 Wang $\mathrm{H}$, Huff TB, Zweifel DA et al. In vitro and in vivo two-photon luminescence imaging of single gold nanorods. Proc. Natl Acad. Sci. USA 102(44), 15752-15756 (2005).

162 Niidome T, Akiyama Y, Yamagata M et al. Poly(ethylene glycol)-modified gold nanorods as a photothermal nanodevice for hyperthermia. J. Biomater. Sci. Polym. Ed. 20(9), 1203-1215 (2009).

163 Dickerson EB, Dreaden EC, Huang X et al. Gold nanorod assisted near-infrared plasmonic photothermal therapy
(PPTT) of squamous cell carcinoma in mice. Cancer Lett. 269(1), 57-66 (2008).

164 Kenny GD, Kamaly N, Kalber TL et al. Novel multifunctional nanoparticle mediates siRNA tumour delivery, visualisation and therapeutic tumour reduction in vivo. J. Control. Release 149(2), 111-116 (2011).

165 Mertz D, Affolter-Zbaraszczuk C, Barthes J et al. Templated assembly of albumin-based nanoparticles for simultaneous gene silencing and magnetic resonance imaging. Nanoscale 6(20), 11676-11680 (2014).

166 Mertz D, Tan P, Wang Y, Goh TK, Blencowe A, Caruso F. Bromoisobutyramide as an intermolecular surface binder for the preparation of free-standing biopolymer assemblies. $A d v$. Mater. 23(47), 5668-5673 (2011).

167 Bae KH, Lee JY, Lee SH, Park TG, Nam YS. Optically traceable solid lipid nanoparticles loaded with siRNA and paclitaxel for synergistic chemotherapy with in situ imaging. Adv. Healthc. Mater. 2(4), 576-584 (2013).

168 Taruttis A, Lozano N, Nunes A et al. siRNA liposome-gold nanorod vectors for multispectral optoacoustic tomography theranostics. Nanoscale 6(22), 13451-13456 (2014).

169 Prabhu RH, Patravale VB, Joshi MD. Polymeric nanoparticles for targeted treatment in oncology: current insights. Int. J. Nanomed. 10, 1001-1018 (2015).

170 Press AT, Traeger A, Pietsch C et al. Cell type-specific delivery of short interfering RNAs by dye-functionalised theranostic nanoparticles. Nat. Commun. 5, 5565 (2014).

171 Karlgren M, Ahlin G, Bergstrom CaS, Svensson R, Palm $\mathrm{J}$, Artursson P. In vitro and in silico strategies to identify OATP1B1 inhibitors and predict clinical drug-drug interactions. Pharm. Res. 29(2), 411-426 (2012).

172 Ki MH, Kim JE, Lee YN et al. Chitosan-based hybrid nanocomplex for siRNA delivery and its application for cancer therapy. Pharm. Res. 31(12), 3323-3334 (2014).

173 Li S, Huang L. In vivo gene transfer via intravenous administration of cationic lipid-protamine-DNA (LPD) complexes. Gene Ther. 4(9), 891-900 (1997).

174 Yuan H, Zhang W, Du YZ, Hu FQ. Ternary nanoparticles of anionic lipid nanoparticles/protamine/DNA for gene delivery. Int. J. Pharm. 392(1), 224-231 (2010).

175 Greish K. Enhanced permeability and retention of macromolecular drugs in solid tumors: a royal gate for targeted anticancer nanomedicines. J. Drug Target. 15(7), 457-464 (2007).

176 Juliano R, Bauman J, Kang H, Ming X. Biological barriers to therapy with antisense and siRNA oligonucleotides. Mol. Pharm. 6(3), 686-695 (2009).

177 Marchal C, Redondo M, Padilla M et al. Expression of prostate specific membrane antigen (PSMA) in prostatic adenocarcinoma and prostatic intraepithelial neoplasia. Histol. Histopathol. 19(3), 715-718 (2004).

178 Perner S, Hofer MD, Kim R et al. Prostate-specific membrane antigen expression as a predictor of prostate cancer progression. Hum. Pathol. 38(5), 696-701 (2007).

179 Yao V, Parwani A, Maier C, Heston WD, Bacich DJ. Moderate expression of prostate-specific membrane antigen, a tissue differentiation antigen and folate hydrolase, facilitates 
prostate carcinogenesis. Cancer Res. 68(21), 9070-9077 (2008).

180 Malet-Martino M, Jolimaitre P, Martino R. The prodrugs of 5-fluorouracil. Curr. Med. Chem. Anticancer Agents 2(2), 267-310 (2002).

181 Li C, Penet MF, Winnard P Jr., Artemov D, Bhujwalla ZM. Image-guided enzyme/prodrug cancer therapy. Clin. Cancer. Res. 14(2), 515-522 (2008).

182 Glunde K, Ackerstaff E, Mori N, Jacobs MA, Bhujwalla ZM. Choline phospholipid metabolism in cancer: consequences for molecular pharmaceutical interventions. Mol. Pharm. 3(5), 496-506 (2006)

183 Glunde K, Jie C, Bhujwalla ZM. Molecular causes of the aberrant choline phospholipid metabolism in breast cancer. Cancer Res. 64(12), 4270-4276 (2004).
184 Kozikowski AP, Nan F, Conti P et al. Design of remarkably simple, yet potent urea-based inhibitors of glutamate carboxypeptidase II (NAALADase). J. Med. Chem. 44(3), 298-301 (2001).

185 Banerjee SR, Pullambhatla M, Byun Y et al. Sequential SPECT and optical imaging of experimental models of prostate cancer with a dual modality inhibitor of the prostate-specific membrane antigen. Angew. Chem. Int. Ed. Engl. 50(39), 9167-9170 (2011).

186 Li C, Penet MF, Wildes F et al. Nanoplex delivery of siRNA and prodrug enzyme for multimodality image-guided molecular pathway targeted cancer therapy. ACS Nano 4(11), 6707-6716 (2010) 